\title{
ESTIMATING THE EMPLOYMENT EFFECTS OF RECENT MINIMUM WAGE CHANGES: EARLY EVIDENCE, AN INTERPRETATIVE FRAMEWORK, AND A PRE-COMMITMENT TO FUTURE ANALYSIS
}

\author{
Jeffrey Clemens \\ Michael R. Strain \\ Working Paper 23084 \\ http://www.nber.org/papers/w23084 \\ NATIONAL BUREAU OF ECONOMIC RESEARCH \\ 1050 Massachusetts Avenue \\ Cambridge, MA 02138 \\ January 2017
}

We thank Wendy Morrison for excellent research assistance. Clemens is grateful to the University of Texas at Austin's Harrington Faculty Fellows Program and to the Stanford Institute for Economic Policy Research for their financial assistance and hospitality while writing this paper. The views expressed herein are those of the authors and do not necessarily reflect the views of the National Bureau of Economic Research.

NBER working papers are circulated for discussion and comment purposes. They have not been peer-reviewed or been subject to the review by the NBER Board of Directors that accompanies official NBER publications.

(C) 2017 by Jeffrey Clemens and Michael R. Strain. All rights reserved. Short sections of text, not to exceed two paragraphs, may be quoted without explicit permission provided that full credit, including $\odot$ notice, is given to the source. 
Estimating the Employment Effects of Recent Minimum Wage Changes: Early Evidence, an Interpretative Framework, and a Pre-Commitment to Future Analysis

Jeffrey Clemens and Michael R. Strain

NBER Working Paper No. 23084

January 2017

JEL No. H11,J08,J23,J38

\begin{abstract}
$\underline{\text { ABSTRACT }}$
This paper presents early evidence on the employment effects of state minimum wage increases enacted between January 2013 and January 2015, and offers an interpretative framework to understand why it is of interest to study recent changes in isolation. Given the ongoing transitions of many states' minimum wage rates, we also set the stage for a pre-committed analysis of the minimum wage changes scheduled for coming years. Through 2015, we estimate that employment among young adults and young individuals with less than a completed high school education expanded modestly less quickly in states that enacted one-time or multi-phase statutory minimum wage increases than in states that enacted no minimum wage increases. Across the specifications we implement and the samples we analyze, many of our estimates are statistically indistinguishable from zero. Data on the longer-run effects of this period's minimum wage changes will be essential for more fully assessing these changes' effects and for drawing strong conclusions regarding how minimum wage increases affect employment in this decade's institutional and economic environment. As data become available for the full 2016 through 2019 calendar years, we will execute and report the results of analyses that follow the road map this paper develops.
\end{abstract}

\author{
Jeffrey Clemens \\ Department of Economics \\ University of California, San Diego \\ 9500 Gilman Drive \#0508 \\ La Jolla, CA 92093 \\ and NBER \\ jeffclemens@ucsd.edu \\ Michael R. Strain \\ American Enterprise Institute \\ 1789 Massachusetts Avenue, NW \\ Washington, DC 20036 \\ michael.strain@aei.org
}


In the years following the Great Recession, there was a lull in both state and federal efforts to increase minimum wages. Following the federal minimum wage's July 2009 rise to $\$ 7.25$, few states enacted new statutory minimum wage changes through the end of 2012 . The increases that occurred were primarily linked to state statutes that provide for annual indexing of their minimum wage rates for inflation.

In contrast, a significant number of state-level minimum wage policy changes have taken place since January 2013. On a January-to-January basis, one-time or multi-phase statutory minimum wage changes were enacted by 1 state from 2012 to 2013, 4 from 2013 to 2014, and 17 from 2014 to 2015 . Across these states, the average increase enacted between January 2012 and January 2015 was $\$ 0.92$. Over this same time period, the minimum wage rose by an average of $\$ 0.46$ across the 9 states that indexed annually for inflation. Many additional minimum wage changes have since taken effect, including 19 state-level changes implemented in January $2017 .^{2}$

This paper presents early estimates of the employment effects of the first waves of the minimum wage increases described above. More importantly, given the ongoing implementation of states' multi-phase minimum wage increases, we set the stage for a pre-committed analysis of these minimum wage changes' effects over coming years. As data become available for the full 2016 through 2019 calendar years, we will execute and report the results of analyses that follow the road map laid out below.

We interpret changes in employment and wages through the lens of a conceptual framework developed by Clemens and Wither (2014). ${ }^{3}$ The framework is well suited for this

\footnotetext{
${ }^{2}$ Note that slightly different counts of states are obtained when making year-over-year rather than January-toJanuary comparisons. We classify the District of Columbia as a state for these tabulations. We do not include New Jersey in our list of "indexers" because it had not begun indexing its minimum wage rate for inflation until 2014. ${ }^{3}$ The framework appears in a revision of Clemens and Wither's 2014 NBER working paper. That revision can be found here: http://econweb.ucsd.edu/ j1 clemens/pdfs/ClemensWitherMinimumWageGreatRecession.pdf
} 
purpose because it concisely captures the economic intuitions that underlie both the intended and unintended consequences of the minimum wage. The framework accomplishes this by connecting analytic descriptions of the minimum wage's effects to the combination of market and institutional forces that shape wage rates at the low end of the skill distribution. It highlights that the minimum wage's capacity to increase workers' wages depends on the magnitude of bargaining frictions. With regards to employment, it links the minimum wage's effects to the determinants of demand for low-skilled labor. A key insight that follows naturally from this framework is that the response of employment to a change in the minimum wage may vary significantly across settings. Consequently, historical estimates of minimum wage effects may provide little guidance regarding the effects of the minimum wage changes that have been recently enacted. This motivates our effort to analyze these changes' effects in isolation. We summarize the framework's key features in section 1.

In section 2, we survey the minimum wage literature's most recent developments. Our survey emphasizes 2 points of interest. First, we briefly discuss the recent literature's lack of consensus regarding the employment effects of historical minimum wage changes. Because minimum wage changes may have quite different effects across settings, we emphasize that the literature's lack of consensus has little bearing on the need for fresh analysis of more recent minimum wage changes' effects. Second, we highlight the recent literature's more generalizable theoretical insights, which may aid in interpreting estimates from both past and future analyses.

In sections 3, 4 and 5, we set the stage for our empirical analysis. Section 3 provides further background regarding the minimum wage changes we analyze. Section 4 discusses the data sources we utilize. Section 5 then describes the regression specifications we implement. 
Our initial analysis follows a standard difference-in-differences strategy. ${ }^{4} \mathrm{We}$ complement this analysis with a triple-difference research design. The triple-difference design nets out employment trends among individuals in skill groups that are not affected by the minimum wage as an approach to controlling for cross-state variations in labor market conditions over time.

Section 6 presents our short-run estimates of the effects of state minimum wage changes implemented between January 2013 and January 2015. Our overall reading of the evidence is that, through 2015, recent minimum wage increases have modestly held back employment among young adults and young high school dropouts. Our best estimate is that employment expanded one percentage point less among low-skilled groups in states that implemented onetime or multi-phase statutory minimum wage increases than in states that did not increase their minimum wage rates. The disemployment effects we find are particularly stable across the specifications we estimate on a sample of the least-skilled, least-experienced workers.

While some of the estimates we present are distinguishable from zero at conventional significance levels, many are not. Because the follow-up (or "post") period for this initial wave of analysis consists only of 2015 , we are reluctant to draw strong qualitative conclusions. The uncertainty underlying our estimates highlights the need for future data on longer-run effects. In this regard, the early evidence from the cross-state experience resembles early estimates from the Seattle Minimum Wage Study (Hill et al, 2016).

We analyze two data sets, the basic Current Population Survey (CPS) and the Merged Outgoing Rotation Groups (MORG) of the CPS. Our estimates are moderately larger in

\footnotetext{
${ }^{4}$ Our strategy is similar to that employed in a recent analysis by members of the President Obama's Council of Economic Advisers (CEA). The primary difference is that we analyze samples selected on the basis of age or both age and education, while the CEA analysis (Black, Furman, Giuliano, and Powell, 2016) focuses on industries that disproportionately employ low-skilled workers.
} 
magnitude and are more frequently statistically significant when we analyze the CPS-MORG than when we analyze the basic CPS. This raises the question of whether the difference arises due to sampling variations or differences in data quality. ${ }^{5}$ Future years of data may help to answer this question. The difference is relevant in part because the CPS-MORG files permit analysis of a richer set of earnings-related outcomes than do the basic CPS files. When researchers turn to analyses of these outcomes, it must thus be kept in mind that the underlying employment impacts appear larger in the CPS-MORG samples than in the larger samples from the basic CPS.

Finally, negative point estimates are more pervasively linked to one-time or multi-phase statutory minimum wage changes than to the minimum wage changes generated by inflation indexing provisions. As highlighted by Strain and Brummund (2016), the employment effects of indexation provisions may be concentrated over the years immediately following their implementation. The responses of forward looking firms should not be expected to coincide with each year's modest and forecastable inflation adjustment. Dynamic considerations of this sort are consistent with recent insights from work by Sorkin (2015) and Aaronson, French, and Sorkin (Forthcoming).

In section 7 we offer concluding remarks. Our overall assessment is that strong conclusions must await the arrival and analysis of data for years beyond 2015. Future estimates will benefit from their ability to track the relatively medium- to long-run effects of this period's minimum wage changes, many of which have yet to be fully implemented. The capacity for

\footnotetext{
${ }^{5}$ Differences between results obtained using the basic CPS and CPS-MORG files underlie a recent exchange involving Sabia, Burkhauser, and Hansen (2012), Hoffman (2016), and Sabia, Burkhauser, and Hansen (2016).
} 
future estimates to describe long-run effects may prove more important than their ability to draw on larger quantities of data per se.

Future analyses will also be better positioned to account for potentially confounding economic factors that emerge as being relevant to this research setting. To date, for example, it is unknown whether economic forces ranging from immigration to trade to technology have differentially affected local labor markets in ways that are correlated with this period's minimum wage changes. As knowledge deepens regarding these factors' relevance to local labor markets' post-recession recoveries, it will become possible to tailor research designs to more fully take these forces into account.

\section{Section I: A Framework for Characterizing the Minimum Wage's Effects}

This section introduces a straightforward framework for characterizing the minimum wage's effects on employment and on the wage distribution. ${ }^{6}$ The framework follows the dichotomy of Bound and Johnson (1992) in describing wage rates as arising from a combination of competitive market forces and bargaining institutions. Individual $i$ 's productivity, the product of the quantity and market price of his or her output, is $a_{\mathrm{i}}$ per hour. Firms maximize profits by employing all individuals they can hire at wage rates less than or equal to $a_{\mathrm{i}}$. Absent binding minimum wage regulation, firms offer individual $i$ a wage of $\theta_{\mathrm{i}} a_{\mathrm{i}}$. If workers are paid precisely their marginal product, $\theta_{\mathrm{i}}=1$. When $\theta_{\mathrm{i}}<1$, workers are paid less than their marginal product. If

\footnotetext{
${ }^{6}$ This framework is based on Clemens and Wither (2014), from which some portions of this section's text are drawn. We focus here exclusively on the demand side factors underlying wage and employment determination. Clemens and Wither (2014) allow for supply side factors through the introduction of individual-specific reservation wage rates. The simplified framework we present here omits the supply side because it is not relevant to the insights we emphasize. We note at the outset that the framework says little about the dynamics of the minimum wage's effects. We defer a discussion of dynamic considerations until section II.
} 
$\theta_{\mathrm{i}}<1$, there is room for a minimum wage to transfer resources from firms to workers without reducing employment. The bargaining parameter $\theta_{\mathrm{i}}$, which is central to this possibility, may vary in magnitude due to a variety of labor market frictions (Manning, 2011).

The statutory minimum wage, $\mathrm{w}_{\min }$, may constrain firms' wage offers. So long as $a_{\mathrm{i}} \geq$ $\mathrm{W}_{\min }$, so that the value of the individual's expected output equals or exceeds the statutory minimum wage, a profit maximizing firm will offer employment at $\mathrm{w}_{\min }$ when $\theta_{\mathrm{i}} a_{\mathrm{i}}<\mathrm{w}_{\min }$. When $a_{\mathrm{i}}<\mathrm{w}_{\min }$, on the other hand, the firm will not offer the individual employment. The market and institutional forces captured by $\theta_{\mathrm{i}}$ and $a_{\mathrm{i}}$ thus enable the framework to describe the minimum wage's primary intended and unintended effects.

To summarize: Let $w_{\mathrm{i}}$ be individual $i$ 's observed wage. If a firm's unconstrained wage offer is not bound by the minimum wage, individual $i$ will be employed at a wage of $w_{\mathrm{i}}=\theta_{\mathrm{i}} a_{\mathrm{i}}$. If $\theta_{\mathrm{i}} a_{\mathrm{i}}<\mathrm{w}_{\min }$ and $a_{\mathrm{i}} \geq \mathrm{w}_{\min }$, the firm will employ the individual at the minimum wage $\left(w_{\mathrm{i}}=\mathrm{w}_{\min }\right)$, but would have offered less if not constrained. Finally, the individual is out of work and has an observed wage of $w_{\mathrm{i}}=0$ if $a_{\mathrm{i}}<\mathrm{w}_{\min }$.

In the policy debate, minimum wage advocates typically intend for minimum wage increases to transfer income to workers out of their employers' profits. In this framework, that transfer can be large when the bargaining position of workers $\left(\theta_{i}\right)$ is relatively weak. Minimum wage opponents typically worry that increases will erode the labor market opportunities of lowskilled workers. In this framework, that employment effect can be large when the market value of many workers' output $\left(a_{\mathrm{i}}\right)$ is low relative to the level of the minimum wage. The overall impact of the minimum wage, then, depends on its level relative to the productivity of prospective workers and on the bargaining power those workers possess when negotiating wage rates with prospective employers. 
We now take a somewhat deeper analytic look at the minimum wage's employment effects. Within this framework, the minimum wage's effect on the overall rate of employment depends on where the minimum wage falls within the productivity distribution. At time $t$, let $a_{\mathrm{i}}$ be distributed according to the probability density function $f_{t}(\cdot)$. The employment loss linked to a minimum wage of $\mathrm{w}_{\min }$ is then

$$
\int_{0}^{w_{\min }} f_{t}\left(a_{i}\right) d\left(a_{i}\right)
$$

Equation (1) shows straightforwardly that the employment loss linked to the minimum wage will be large when the productivity of many individuals falls below it. This follows directly from the assumption that profit maximizing firms will only employ workers whose output has greater market value than the cost of employing them. ${ }^{7}$ Both increases in the statutory minimum wage and decreases in the value of the goods and services a prospective worker would produce can increase the share of the workforce that lacks employment for this reason.

Equation (1) is informative regarding two further, related questions of interest. First, how much employment loss should we expect to result from increasing the minimum wage? Equation (1) makes clear that the employment loss due to a change in the minimum wage depends on the density of the productivity distribution between the minimum wage's old and new levels. Similarly, the wage gains associated with a minimum wage increase depend on the distribution of $\theta_{\mathrm{i}} a_{\mathrm{i}}$ between the minimum wage's old and new levels. The density of these

\footnotetext{
${ }^{7}$ In the simple framework developed here, the worker's wage is the only cost of employment to the firm. A more general model would highlight that the relevant employment costs include the costs of benefits, training, and regulatory compliance. A still richer model would emphasize uncertainties regarding workers' abilities and the dynamics of human capital development. In a multi-year contract, for example, it need not be the case that $a_{\mathrm{i}} \geq \mathrm{w}_{\mathrm{i}}$, at all points in time or even over the life of any one worker's contract. Profit maximization requires only that the expected value of a worker's output exceeds expected employment costs over the course of the worker's contract.
} 
distributions may, of course, vary significantly across settings. Minimum wage changes that move through thin portions of the productivity distribution will tend to have small employment effects while changes that move through thick portions can have large effects.

Additional factors may either dampen or augment the effect one would infer from the baseline productivity distribution. Perhaps most importantly, a minimum wage increase may alter the productivity distribution itself. This may occur through changes in both "real" and "nominal" productivity. Nominal productivity will rise with the minimum wage when minimum wage increases are passed onto consumers in the form of higher prices. With regards to equation (1), this is germane because the relevant notion of productivity is "revenue product," meaning the quantity of output the worker produces multiplied by its market price. The minimum wage may also alter real productivity if it affects production arrangements, worker effort, or the skill composition of the workforce itself, among other factors.

Second, how will the employment effects of a given minimum wage evolve over time? This depends on how the productivity distribution evolves over time. Observing once more that $a_{\mathrm{i}}$ is nominal productivity, the relevant distribution can be shifted by either inflation or real productivity growth. The employment effect of a given minimum wage will thus be more sustained when inflation and real productivity growth are slow than when they are rapid. Relatedly, either deflation or a negative labor demand shock will increase the employment loss linked to a given minimum wage. In the face of such shocks, the minimum wage acts as a source of rigidity that mediates the transmission of the shock into some ensuing combination of wage and employment changes.

A final point worth emphasizing is that the prices and/or price indices relevant to the minimum wage's effects may differ from the general price level. The relevant prices are the 
market prices of the outputs low-skilled workers produce. These prices can be affected by factors other than general inflation. They can be affected, for example, by the evolution of the technologies through which goods in low-skill-intensive industries are produced. The introduction of a technology that substitutes for low-skilled labor at lower cost, for example, can reduce the prices of the goods low-skilled individuals produce. The introduction of such a technology would thus result in a downward shift of the relevant productivity distribution. This, in turn, would increase the employment loss associated with a given minimum wage. A similar analysis can be applied to expansions of trade with countries that are lower cost producers of the goods low-skilled workers produce in the United States.

\section{Section II: Insights from the Recent Minimum Wage Literature}

This section overviews three sets of developments from the last decade of research on the minimum wage's effects. Sub-section II.1 briefly discusses the recent literature on the minimum wage's relatively short-run employment effects. Sub-section II.2 discusses additional lines of research that are relevant for understanding the minimum wage's effects on the real wage distribution. Sub-section II.3 discusses developments in the literature's understanding of the dynamics of the labor market's responses to minimum wage changes.

\section{Section II.1: The Recent Literature on the Minimum Wage's Employment Effects}

The recent literature on the minimum wage's employment effects has generated little consensus. Recent analyses include work by Neumark, Salas, and Wascher (2013), Allegretto, Dube, Reich, and Zipperer (Forthcoming), Clemens and Wither (2014), Clemens (2015), 
Zipperer (2016), Dube and Zipperer (2016), Powell (2016), and Meer and West (2016). While there is little consensus, a common thread distinguishes papers that emphasize negative effects from papers that emphasize null effects. Statistically insignificant estimates of employment elasticities tend to be obtained by authors who significantly constrain the variation in state and federal minimum wage policy that is used to estimate the minimum wage's effects. ${ }^{8}$ Negative effects tend to be estimated by authors who harness a relatively large fraction of the policy variation at hand. ${ }^{9}$ The key issue, then, is how one evaluates prevailing approaches to constraining variation. That is, the question is whether the prevailing sample selection criteria and saturated econometric models are essential for reducing bias, are introducing their own biases, or are simply reducing statistical power. ${ }^{10}$ We do not attempt to resolve these issues here.

\section{Section II.2: Evidence on Additional Effects on the Real Wage Distribution}

Despite a lack of consensus regarding the minimum wage's employment effects, the recent minimum wage literature has generated a variety of interesting insights. Two key lines of

\footnotetext{
${ }^{8}$ The relevant papers include Allegretto, Dube, Reich, and Zipperer (Forthcoming), Zipperer (2016), and Dube and Zipperer (2016).

${ }^{9}$ The relevant papers include Neumark, Salas, and Wascher (2013), Clemens and Wither (2014), Clemens (2015), Powell (2016), and Meer and West (2016).

${ }^{10}$ The phrase "saturated econometric models" refers to models that include large covariate sets as controls. Common examples involve the inclusion of state-specific trends and even larger sets of interactions between monthly or quarterly time indicator variables and indicator variables for each of the 9 census divisions (that is, $12 \mathrm{x}$ $9=108$ control variables for each year covered by the sample) or 4 census regions. Additional control sets of interest involve interactions between time effects and variables that describe states' baseline characteristics. While it may initially sound odd for the inclusion of such control sets to be described as a potential source of bias, the channels through which bias can be introduced are broadly recognized. It is commonly recognized, for example, that "controlling" for state-specific trends can bias estimates towards 0 when a policy intervention's effects unfold dynamically (see, for example, Wolfers, 2006, or Baum Snow and Lutz, 2011). In the minimum wage context, this point has been made through simulations presented in the 2013 working paper version of Meer and West's (2016) analysis. There are similarly straightforward sources of bias that can be introduced by controlling for interactions between time effects and states" baseline characteristics. A final key issue involves the question of whether "within census region" or "within census division" sources of variation in minimum wages are less prone to generating biased estimates than variations that extend both across and within regions.
} 
insight involve effects that can be central for understanding the minimum wage's impact on the real wage distribution. These include investigations of the minimum wage's effects on output prices and research on bargaining spillovers.

Research on the minimum wage's effects on output prices includes a series of papers by Daniel Aaronson and co-authors (Aaronson, 2001; Aaronson and French, 2007; Aaronson, French, and MacDonald, 2008). These papers, which focus on output prices in the low-skill intensive restaurant sector, consistently find evidence of positive price pass through. A first implication of these findings is that price pass through blunts the real effects of nominal increases in the minimum wage. From the firms' perspective, the resulting revenue increase partially offsets the underlying cost increase; from the workers' perspective, the increase in their incomes is partially offset by increases in the prices they face as consumers.

A second point is that price pass through can have distributional implications. Working from the strong assumption of complete price pass through, MaCurdy (2015) finds that minimum wage increases are less redistributive than one might expect. This follows from two facts. First, the consumption bundles of low income families are weighted towards goods produced by minimum wage workers. Second, many minimum wage workers are themselves in middle and upper income families.

Aaronson and his co-authors develop a further insight related to market structure. More specifically, they observe that positive price pass through can be used to distinguish between the standard competitive market model and the standard monopsony model. While the competitive market model predicts strong price pass through, the monopsony model has weaker predictions and would, in its most basic form, predict the opposite. 
Additional research considers the possibility of spillovers driven by the minimum wage's effects on workers' bargaining positions. This work emphasizes the bargaining positions of workers initially earning wage rates above the new minimum wage, who are thus not directly affected by the minimum wage changes under analysis. Studies finding positive effects on such individuals' wages include research by Lee (1999), Autor, Manning and Smith (2016), and Engbom and Moser (2016). These studies thus highlight mechanisms through which a minimum wage change's effects may generate more redistribution towards low-skilled workers than one might initially be inclined to expect.

Section II.3: Understanding the Dynamics of a Minimum Wage Change's Effects

The minimum wage literature has been less attentive than many program evaluation literatures to issues involving dynamics. This applies to dynamics over both the period preceding and the period subsequent to a minimum wage change's implementation. On the first point, the minimum wage literature has paid less attention than most literatures to the anticipatory responses that may accompany long lags between a policy change's legislation and enactment. On the second point, much of the literature has similarly disregarded the potential difference between a minimum wage change's short and long run effects.

Inattention to lags between legislation and implementation has been pervasive in the minimum wage literature. In the debate between Neumark, Salas, and Wascher (2013) and Allegretto, Dube, Reich, and Zipperer (Forthcoming), for example, the independent variable of interest in the bulk of the reported specifications is the log of the contemporaneous minimum 
wage. $^{11}$ Although non-trivial implementation lags are the norm, the baseline specifications thus do not take them into account. Similarly, the baseline survey in Card and Krueger's (1993) pioneering case study occurred two years after the relevant minimum wage change had been passed by the New Jersey legislature. ${ }^{12}$

Recent insights from Sorkin (2015) and Aaronson, Sorkin, and French (Forthcoming) highlight the relevance of firms' technology adoption decisions to the dynamics of a minimum wage change's effects. The empirically relevant insight is that effects along this adjustment margin will unfold in part as old-technology firms die and new firms invest in the technologies they expect to maximize their net revenue streams. This dimension of a minimum wage changes' effects may thus occur gradually over an extended period following the underlying legislation's passage. In the context of the canonical New Jersey case study, the 1991 recession was a period of churn between the minimum wage change's legislation and implementation. It is thus a period during which the adjustments emphasized by Sorkin (2015) and Aaronson, Sorkin, and French (Forthcoming) may well have begun to take place. In the analysis we present below, the regression framework is designed to flexibly track employment's evolution over the years subsequent to a pre-legislation baseline.

The literature's focus on contemporaneous minimum wage rates also shapes its attentiveness to the dynamics of short- vs. long-run responses. Interestingly, Neumark and

\footnotetext{
${ }^{11}$ The analysis of Allegretto, Dube, Reich, and Zipperer (Forthcoming) includes a table that considers lags and leads. Because all states' minimum wage rates change many times during the sample, however, it is quite difficult to ascertain what variation underlies the estimated coefficients associated with these variables.

${ }^{12}$ Card and Krueger (2002) summarize the legislative history as follows: "A bill signed into law in November 1989 raised the federal minimum wage from $\$ 3.35$ per hour to $\$ 3.80$ effective April 1, 1990, with a further increase to $\$ 4.25$ per hour on April 1, 1991. In early 1990, the New Jersey legislature went one step further, enacting parallel increases in the state minimum wage for 1990 and 1991 and an increase to \$5.05 per hour effective April 1, 1992." Card and Krueger implemented their baseline telephone survey in February and March of 1992. The survey was thus conducted 2 months prior to the New Jersey minimum wage rate's final increase and 2 years after New Jersey passed the relevant legislation.
} 
Wascher's (1992) pioneering use of state panel data provides one of the literature's more nuanced discussions of dynamic effects. This issue was more recently taken up by Meer and West (2016), who argue that minimum wage changes' employment effects are better modeled as effects on employment growth than as instantaneous effects on levels. The insights of Sorkin (2015) and Aaronson, Sorkin, and French (2013) provide intuitive theoretical support for this perspective. The specifications we implement are designed to allow such effects, if they are relevant, to emerge straightforwardly through our estimates.

\section{Section III: Background on State Minimum Wage Changes between 2011 and 2015}

Our analysis investigates the effects of state minimum wage changes enacted between January 2013 and January 2015. Figure 1 and table 1 show our division of states into those that have been indexing their minimum wage rates for inflation, those that enacted small statutory minimum wage changes over this time period, and those that enacted statutory minimum wage changes totaling at least $\$ 1$ between January 2013 and January 2015. Using Department of Labor (DOL) data on states' prevailing minimum wage rates, we code 8 states as states that enacted minimum wage increases of $\$ 1$ or more, 9 states as states that enacted minimum wage changes less than $\$ 1$, and 9 states as states that have indexed their minimum wage rates to inflation since early in our analysis period. We assign each state to one of these three groups, or to the control group. We do not allow states to be in more than one group - we are, in effect, assigning each state to a policy characteristic. ${ }^{13}$

\footnotetext{
${ }^{13}$ States' designations will increasingly overlap as we extend our analysis samples beyond 2015. In 2014, for example, New Jersey introduced an inflation indexation provision. Several states with longstanding inflation indexation provisions have more recently joined the ranks of the states with statutory minimum wage changes.
} 
Figure 2 shows the time paths of the average effective minimum wages in the states to which we apply each designation. From January 2011 to January 2013, the figure illustrates that minimum wage changes were quite modest and were concentrated primarily among states with inflation indexing provisions. Several states had implemented non-trivial minimum wage changes by January 2014. Substantially more minimum wage raising activity had taken place as of January 2015.

The timing of the minimum wage changes we analyze motivates the regression specifications we implement. Specifically, we estimate the minimum wage's effects from a base period including 2011, 2012, and 2013 through subsequent years. We interpret 2014 as a "Transition" year during which modest increases were implemented and future changes were legislated. Notably, 2015, 2016, and 2017 are all years during which many minimum wage increases have either already been implemented or are scheduled to be implemented. As our future analyses incorporate data from 2016 through 2019, we will thus allow minimum wage changes' accumulated effects to vary across years. That is, we will allow our estimates of these minimum wage changes' transitional, short-, and medium-run effects to vary.

\section{Section IV: Data Sources}

Our regression analysis utilizes data from the basic Current Population Survey (CPS) and from the CPS's Merged Outgoing Rotation Group (MORG) files, as processed by the National Bureau of Economic Research (NBER). In future work, we will incorporate analysis of data from the American Community Survey (ACS). The CPS-MORG files report data for a subset of the observations in the basic CPS. Specifically, these are the individuals from which the CPS 
collects relatively detailed information regarding hours of work, weekly earnings, overtime pay, and the characteristics of secondary jobs.

In the estimates we present below, the distinction between the basic CPS and the CPSMORG has non-trivial relevance for the qualitative conclusions at which one would arrive from our analysis. Though differences in our estimates across these data sets are not statistically distinguishable from one another, estimates tend to be moderately more negative - i.e., the disemployment effect appears stronger — when the sample comes from the CPS-MORG files than when the sample comes from the basic CPS. This is important for future work to bear in mind because analyses of outcomes like weekly earnings can only be conducted using the CPSMORG. For the time being, analyses of such outcomes must come with the caveat that estimates will appear more negative than they would appear in an analysis of the basic CPS's larger samples. A key question, then, is whether the difference is attributable primarily to sampling variations. If that is the case, then the smaller estimates associated with the basic CPS's larger samples would be unambiguously preferred. It is also possible, however, that differences in the basic CPS and CPS-MORG questionnaires and data collection processes result in other differences in the quality of the underlying data. ${ }^{14}$

We supplement the basic CPS and CPS-MORG data with data on macroeconomic covariates that may be relevant as control variables. In the analysis presented below, we control for variations in the recovery of the housing market using the Federal Housing Finance Agency's (FHFA) median house price index. We similarly account for variations in broader labor market

\footnotetext{
${ }^{14}$ Data quality may differ in part because there are differences in the length of the relevant questionnaires. Interestingly, differences between results obtained using the basic CPS and CPS-MORG files underlie a recent back and forth involving Sabia, Burkhauser, and Hansen (2012), Hoffman (2016), and Sabia, Burkhauser, and Hansen (2016). It is not clear whether the issues raised by these authors are relevant to our setting.
} 
developments by controlling directly for employment among skill groups that are largely unaffected by the minimum wage. At this early stage, we emphasize that it is difficult to know precisely what macroeconomic factors will emerge as potential sources of bias for estimators of the sort we implement. Additional covariates of potential interest include personal income per capita, as measured by the Bureau of Economic Analysis, and a "Bartik-style" control for the local labor market implications of national industry trends (Bartik, 1991). Additional variables of this sort can be constructed and integrated into the analysis as needed.

Panels A and B of Figures 3 and 4 present two series relevant for gauging differences in the macroeconomic performance of the groups of states we analyze. Specifically, Panel A presents the evolution of the average house price index across these groups of states. Panel B presents the employment rate for relatively young individuals with high school degrees and individuals over age 30 with less than a completed high school degree. These are thus individuals with skills or experience modestly but not overwhelmingly beyond those of most minimum wage workers.

The house price index reveals that the housing market recovery was particularly strong in states that index their minimum wage rates for inflation and in states that enacted substantial one-time or multi-phase minimum wage increases. Failure to control for variations in macroeconomic conditions may thus bias estimates of the employment effects of this period's minimum wage changes towards positive values. The employment series similarly suggests that economic conditions were stronger in states with substantial minimum wage changes than in other states. Further summary statistics describing the samples we analyze can be found in tables $2 \mathrm{~A}$ and $\mathrm{B}$. 
The remaining panels of the figure display employment trends among the skill groups in our primary analysis samples. These include a sample of all young adults and a sample of young individuals with less than a completed high school education. Employment among low skilled individuals in states with substantial minimum wage changes appears to underperform to a modestly greater degree in the figures constructed using the CPS-MORG files than in the figures constructed using the basic CPS. Additionally, differential employment changes are more apparent in the samples selected on the basis of both age (experience) and education than in the samples selected on the basis of age alone. In the analysis presented below, estimates involving the young adult samples are more sensitive to controlling for the macroeconomic proxies discussed above.

A final point of interest is that the baseline level of employment among low-skilled individuals in states that enacted large statutory minimum wage changes was substantively lower than the baseline levels of these groups' employment in other states. This is a potential concern for our analysis in that low-skilled individuals' employment had more room to recover in these states than in states that enacted no minimum wage changes. Mean reversion would tend to bias our estimates towards positive values.

\section{Section V: Framework for Estimating the Effects of Recent Minimum Wage Changes}

This section presents our regression framework for estimating the effects of recent minimum wage increases. We take a standard program evaluation approach in which we divide states into groups based on the policy changes they have implemented over this time period. We 
then estimate standard difference-in-differences and triple-difference specifications to identify differential changes in employment among low-skilled individuals across groups of states.

Our basic difference-in-differences specification is presented in equation (3) below:

$$
Y_{i, s, t}=\sum_{p(t) \neq 0} \beta_{p(t)} \text { Policy }_{s} \times \text { Period }_{p(t)}+\alpha_{1 s} \text { State }_{s}+\alpha_{2 t} \text { Time }_{t}+X_{i, s, t} \gamma+\varepsilon_{i, s, t}
$$

We estimate equation (3) on samples restricted to the population groups most likely to be affected by the minimum wage. These groups consist of young adults (lesser-experienced workers) and individuals with less than a completed high school education (lesser-skilled workers).

Like any standard difference-in-differences specification, equation (3) controls for sets of state and time fixed effects. The vector $\boldsymbol{X}$ contains sets of control variables that vary across the specifications we estimate. In various specifications, it contains the median house price index, the employment rate among individuals with moderately higher skill levels than the individuals in the analysis sample, and individual-level demographic characteristics.

The variable Policy $_{s}$ is an indicator for whether a state fits into a particular policy group. Each of our specifications include multiple policy groups. In all specifications, we differentiate between states that increase their minimum wage rates due to inflation indexing provisions and states that enacted one-time or multi-phase statutory increases. We also differentiate between states whose statutory increases total $\$ 1$ or more and those whose increases are less than $\$ 1$.

The coefficients of interest are the $\beta_{p(t)}$ on the interaction between Policy and $\operatorname{Period}_{p(t)}$. For the analysis presented below, $\operatorname{Period}_{p(t)}$ is a single indicator for observations that occur in 2015. Because we treat 2014 as a transition year, and thus exclude it from the 
sample, the coefficient $\beta_{p(t)}$ describes differential changes in employment from a base period consisting of 2011, 2012, and 2013 through 2015. When we update this analysis to incorporate data for subsequent years, we will allow the dynamics of recent minimum wage changes' effects to unfold at an annual frequency.

The coefficient $\beta_{p(t)}$ is an estimate of the causal effect of states' minimum wage policy changes under standard, but non-trivial, assumptions. The key assumption is that employment among low-skilled groups would, in the absence of the minimum wage changes we analyze, have evolved similarly across the various groups of states. We investigate this assumption in two ways. First, we investigate the robustness of our estimates to changes in the variables used to control for variations in economic conditions. That is, we examine whether our estimates are robust to including no such controls, to controlling for the housing market's evolution, and to controlling for changes in employment among individuals in moderately higher skill groups. Our updates to this analysis will incorporate further such controls as future research on this period's labor market developments points to additional factors that may be important.

We further investigate threats to the causal interpretation of estimates of $\beta_{p(t)}$ by estimating the triple-difference specification described by equation (4):

$$
\begin{aligned}
Y_{i, s, t}= & \sum_{p(t) \neq 0} \beta_{p(t)} \text { Policy }_{s} \times \text { Period }_{p(t)} \times \text { Target }_{i}+\alpha_{1 s} \text { State }_{s}+\alpha_{2 t} \text { Time }_{t}+\alpha_{3 g} \text { Target }_{g} \\
& +\alpha_{4 s t} \text { State }_{s} \times \text { Time }_{t}+\alpha_{5 \text { gs }_{\text {S }} \text { State }_{s} \times \text { Target }_{g}+\alpha_{6 g t} \text { Time }_{t} \times \text { Target }_{g}} \\
+ & X_{i, s, t} \gamma+\varepsilon_{i, s, t}
\end{aligned}
$$

Equation (4) augments equation (3) with three sets of two-way fixed effects. These include group-by-time-period effects, group-by-state effects, and state-by-time-period effects. These 
controls account for differential changes in employment across skill groups over time, cross-state differences in the relative employment of the "Target" group relative to other skill groups at baseline, and time varying differences in states' economic conditions.

The implications of the triple-difference model's state-by-time-period effects depend on what skill groups are included in the sample. The inclusion of state-by-time-period effects enables the specification to control flexibly for economic factors that vary across states and over time. They control for such factors as they manifest themselves through employment changes among the individuals included in the sample as "within-state control groups." In the tripledifference specifications presented below, the within-state control group consists of the full population ages 26 to 54 .

There is a trade-off in determining how high up the skill distribution one goes to select a within-state control group. Individuals in modestly higher skill groups, for example, may be both directly and indirectly affected by the minimum wage change of interest. Direct effects may arise because individuals in modestly higher skill groups may sometimes work in minimum wage jobs. Alternatively, their modestly higher pay rates may be benchmarked to the minimum wage to preserve a compensation hierarchy within an employing firm. Indirect effects may arise through bargaining spillovers or through firms' substitution of very low-skilled workers for modestly higher skilled workers. By contrast, high skilled individuals may be poor controls. That is, the employment of high skilled individuals may be too stable for such individuals to provide a reasonable counterfactual for the effects of economic shocks on employment among the low skilled; their labor markets may be too different for the comparison to be meaningful. The choice of a within-state control group is thus a dimension of the research design along which judgment is needed. 
Uncertainty regarding the ideal within-state control group may call for a straightforward alternative to implementing the triple-difference specification described by equation (4). One attractive alternative is to present information on the relationship between minimum wage changes and employment across sub-samples of skill groups that fully partition the working age population. Employment changes among various skill groups can potentially be interpreted as evidence of labor-labor substitution, as evidence of other spillovers of economic interest, or as evidence that confounding economic factors are at play. By presenting estimates that span all skill groups, this approach allows informed readers to exercise judgment along these margins. When examining such estimates, at least one point is clear: A credible specification ought not to correlate modest minimum wage changes with substantial changes in employment among high skilled individuals. The factors underlying patterns of employment among high skilled individuals would be obvious sources of bias.

\section{Section VI: Regression Estimates of Recent Minimum Wage Changes' Effects}

This section presents our estimates of the short-run effects of minimum wage changes implemented between January 2013 and January 2015 on employment among young adults and young individuals with less than a completed high school education. The estimates are presented

in tables $3 \mathrm{~A}$ and $\mathrm{B}$ through tables $8 \mathrm{~A}$ and $\mathrm{B}$. In all cases, the samples analyzed in tables labeled A come from the NBER's version of the CPS-MORG. The samples analyzed in tables labeled B come from the basic CPS.

Tables 3 A and B present estimates of equation (3)'s difference-in-differences model on samples selected on the basis of both age and education. The sample consists of individuals ages 
25 and under with less than a completed high school education. The estimates in table 3A reveal that, in the CPS-MORG files, employment among individuals in this group declined by between 1.6 and 2.1 percentage points more in states that enacted statutory minimum wage changes than in states that enacted no minimum wage changes. The results across columns 1 through 4 reveal that this finding is not particularly sensitive to controlling for changes in median house prices, for employment among individuals in moderately higher skill groups, or by including sets of individual-specific age and education dummy variables. The estimates in table $3 \mathrm{~B}$, which involve samples from the basic CPS, are smaller. These estimates range between -0.7 and -1.4 percentage point and are in no cases statistically distinguishable from 0 at even the 10 percent level.

Estimates from tables $3 \mathrm{~A}$ and $3 \mathrm{~B}$ reveal that employment among young individuals with less than a completed high school education increased moderately more in states that index their minimum wage rates for inflation than in states that enacted no minimum wage changes over this time period. Across both tables, these estimates range between 0.4 and 1.1 percentage points and are in all cases within 1 standard error of 0 . While the estimates thus suffer from limited precision, the evidence is suggestive that the employment consequences of long forecastable minimum wage increases differ from those of one-time or multi-phase statutory minimum wage changes.

Tables $4 \mathrm{~A}$ and $4 \mathrm{~B}$ present estimates analogous to those in tables $3 \mathrm{~A}$ and $3 \mathrm{~B}$ on samples that consist of all young adults between the ages of 16 and 21 . On this group, estimated effects of one-time or multi-phase minimum wage increases are uniformly negative, but again estimated with limited statistical precision. The estimates on this sample are more sensitive to the inclusion of controls related to the housing market and employment among moderately higher 
skilled individuals. Across the specifications presented, estimates range from -0.4 to -1.9 percentage points on the CPS-MORG samples and from -0.3 to -1.5 percentage points on the basic CPS samples.

A puzzling difference between the analyses of the young adult samples and the samples of high school dropouts involves the employment changes correlated with inflation indexing provisions. While employment among young individuals with less than a completed high school education was positively correlated with inflation indexing provisions, employment among all individuals ages 16 to 21 is, with the exception of one sample and one specification, negatively associated with inflation indexing provisions. Across the estimates presented in tables $4 \mathrm{~A}$ and $4 \mathrm{~B}$, point estimates for the estimated effects of inflation indexing provisions range from -2.4 to 0.1 percentage points.

Tables $5 \mathrm{~A}$ and $\mathrm{B}$ and $6 \mathrm{~A}$ and $\mathrm{B}$ present estimates similar to those presented in tables $3 \mathrm{~A}$ and $\mathrm{B}$ and $4 \mathrm{~A}$ and $\mathrm{B}$, but for which we have divided the sets of states with statutory minimum wage changes on the basis of the magnitudes of the minimum wage changes they implemented. More specifically, we divide these groups of states based on whether the sum of their minimum wage changes between January 2013 and January 2015 was at least $\$ 1$ or less than $\$ 1$. The estimates in table $5 \mathrm{~A}$ show that the negative employment estimates from table $3 \mathrm{~A}$ load primarily onto individuals in states in which statutory minimum wage changes were at least $\$ 1$. In tables 5 A, for example, the point estimate for this group ranges from -2.2 to -2.7 percentage points while the point estimates for states with increases less than $\$ 1$ range from -0.5 to - 1.2 percentage points. Estimates using the basic CPS are again more modest in magnitude. A similar description applies to table 6A and 6B's estimates on samples of young adults ages 16 to 21 . 
The estimates in tables $7 \mathrm{~A}$ and $\mathrm{B}$ and $8 \mathrm{~A}$ and $\mathrm{B}$ are of the triple-difference model described by equation (4). The results provide evidence that the estimates from earlier tables are not driven by economic forces that shaped employment among prime aged individuals across the various groupings of states. For one-time and multi-phase statutory minimum wage changes, point estimates from the triple-difference models are, in essentially all cases, economically indistinguishable from point estimates from the difference-in-differences models. In the tripledifference specifications, estimates associated with inflation indexing provisions are generally closer to 0 than estimates from the analogous difference-in-differences models.

\section{Section VII: Discussion and Conclusion}

This paper presents early estimates of the employment effects of state minimum wage increases implemented between January 2013 and January 2015. Through 2015, our best estimate is that employment among young high school dropouts and young adults expanded one percentage point less in states that enacted one-time or multi-phase statutory minimum wage increases than in other states. We emphasize that given the short "post" period we analyze, data on the longer-run effects of this period's minimum wage changes will be essential for arriving at strong conclusions regarding their effects.

We close by briefly summarizing the analysis plan we will implement as we continue our assessment of the effects of this period's minimum wage changes. Data on both employment and our macroeconomic control variables are now becoming available for the entirety of the 2016 calendar year. Our initial analysis of the 2016 data will thus involve straightforwardly extending the template used in the current paper's analysis. We will account for the minimum 
wage changes implemented in late 2015 and early 2016 by updating the variables we use to describe states' minimum wage policy changes. The construction of all control sets will remain the same.

Our future analyses of 2017 through 2019 data will benefit from the accumulation of knowledge regarding the relevance of forces including immigration, trade, and technology for local labor markets over this time period. We will adapt our analyses of 2017, 2018, and 2019 data to take such developments into account. That is, for analyses that incorporate data beyond 2016, we will supplement our straightforward extensions of the current paper's template with additional analyses designed to account for this period's unique economic developments. Further, we will expand the set of outcome variables to include hours of work, the nature of part time employment, and weekly earnings. As needed, our analyses will incorporate the program evaluation insights discussed above. 


\section{References}

Aaronson, Daniel. "Price pass-through and the minimum wage." Review of Economics and Statistics 83.1 (2001): 158-169.

Aaronson, Daniel, and Eric French. "Product market evidence on the employment effects of the minimum wage." Journal of Labor Economics 25.1 (2007): 167-200.

Aaronson, Daniel, Eric French, and James MacDonald. "The minimum wage, restaurant prices, and labor market structure." Journal of Human Resources43.3 (2008): 688-720.

Aaronson, Daniel, Eric French, Isaac Sorkin, and Ted To. "Industry Dynamics and the Minimum Wage: A Putty-Clay Approach." International Economic Review (Forthcoming).

Allegretto, Sylvia, et al. "Credible Research Designs for Minimum Wage Studies: A Response to Neumark, Salas, and Wascher." Industrial \& Labor Relations Review (Forthcoming).

Baum-Snow, Nathaniel, and Byron F. Lutz. "School desegregation, school choice, and changes in residential location patterns by race." The American Economic Review 101.7 (2011): 30193046.

Bartik, Timothy J. Who Benefits from State and Local Economic Development Policies? Upjohn Press (1991).

Black, Sandra Jason Furman, Laura Giuliano, Wilson Powell. "Minimum wage increases by US states fueled earnings growth in low wage jobs." VoxEU. December 2, 2016.

Bound, John. "Changes in the Structure of Wages in the 1980's: An Evaluation of Alternative Explanations." The American Economic Review 82.3 (1992): 371-392.

Card, David, and Alan B. Krueger. Minimum wages and employment: A case study of the fast food industry in New Jersey and Pennsylvania. No. w4509. National Bureau of Economic Research, 1993.

Clemens, Jeffrey, and Michael Wither. "The minimum wage and the Great Recession: Evidence of effects on the employment and income trajectories of low-skilled workers." No. w20724.

National Bureau of Economic Research, 2014.

Clemens, Jeffrey. "The Minimum Wage and the Great Recession: Evidence from the Current Population Survey.” No. w21830. National Bureau of Economic Research, 2015.

Dube, Arindrajit, and Ben Zipperer. "Pooled synthetic control estimates for recurring treatments: an application to minimum wage case studies." Unpublished Manuscript (2013).

Engbom, Niklas, and Christian Moser. "Earnings Inequality and the Minimum Wage: Evidence from Brazil." Unpublished Manuscript (2016).

Hill, Heather, Jennifer J. Otten, Emma van Inwegen, and Jacob Vigdor. "Early Evidence on the Impact of Seattle’s Minimum Wage Ordinance." Unpublished Manuscript (2016). 
Hoffman, Saul D. "Are the effects of minimum wage increases always small? A reanalysis of Sabia, Burkhauser, and Hansen." Industrial \& Labor Relations Review 69.2 (2016): 295-311.

MaCurdy, Thomas. "How effective is the minimum wage at supporting the poor?." Journal of Political Economy 123.2 (2015): 497-545.

Manning, Alan. "Imperfect competition in the labor market." Handbook of Labor Economics 4 (2011): 973-1041.

Meer, Jonathan, and Jeremy West. Effects of the Minimum Wage on Employment Dynamics. No. w19262. National Bureau of Economic Research, 2013.

Meer, Jonathan, and Jeremy West. "Effects of the Minimum Wage on Employment Dynamics." Journal of Human Resources 51.2 (2016): 500-522.

Neumark, David, JM Ian Salas, and William Wascher. "Revisiting the Minimum WageEmployment Debate: Throwing Out the Baby with the Bathwater?" Industrial \& Labor Relations Review 67.3 suppl (2014): 608-648.

Neumark, David, and William Wascher. "Employment effects of minimum and subminimum wages: panel data on state minimum wage laws." Industrial \& Labor Relations Review 46.1 (1992): 55-81.

Powell, David. "Synthetic Control Estimation Beyond Case Studies." Unpublished Manuscript (2016).

Sabia, Joseph J., Richard V. Burkhauser, and Benjamin Hansen. "Are the effects of minimum wage increases always small? New evidence from a case study of New York state." Industrial \& Labor Relations Review 65.2 (2012): 350-376.

Sabia, Joseph J., Richard V. Burkhauser, and Benjamin Hansen. "When Good Measurement Goes Wrong New Evidence That New York State's Minimum Wage Reduced Employment." Industrial \& Labor Relations Review 69.2 (2015): 312-319.

Sorkin, Isaac. "Are there long-run effects of the minimum wage?." Review of Economic Dynamics 18.2 (2015): 306-333.

Strain, Michael R., and Peter Brummund. "Real and permanent minimum wages." $A E I$ Economics Working Papers No. 875967. 2016.

Wolfers, Justin. "Did unilateral divorce laws raise divorce rates? A reconciliation and new results." The American Economic Review 96.5 (2006): 1802-1820. 


\section{Table 1: List of statutory increasers and indexers}

\begin{tabular}{ll} 
Statutory increasers of \$1 or more & Statutory increasers under \$1 \\
\cline { 2 - 2 } Alaska & Arkansas \\
California & Connecticut \\
District of Columbia & Delaware \\
Massachusetts & Hawaii \\
New Jersey & Maryland \\
New York & Michigan \\
Rhode Island & Minnesota \\
South Dakota & Nebraska \\
Indexers & West Virginia \\
Arizona & \\
Colorado & \\
Florida & \\
Missouri & \\
Montana & \\
Ohio & \\
Oregon & \\
Vermont & \\
Washington & \\
&
\end{tabular}

Notes: Data on minimum wage indexing provisions comes from the National Council of State Legislatures. The states labeled as Indexers link annual updates to their effective minimum wage rates to a measure of the cost of living. That measure is typically, but not in all cases, based on the Consumer Price Index. Data on minimum wage changes comes from the Department of Labor. States are counted as statutory increasers of under $\$ 1$ if the combined statutory increase in the minimum wage from January 2013 through January 2015 was under $\$ 1$. States are counted as statutory increasers of $\$ 1$ or more if the combined statutory increase in the minimum wage was $\$ 1$ or more. 
Table 2A: Summary Statistics CPS-MORG data

Panel A: Employment-to-population ratio by group and state category

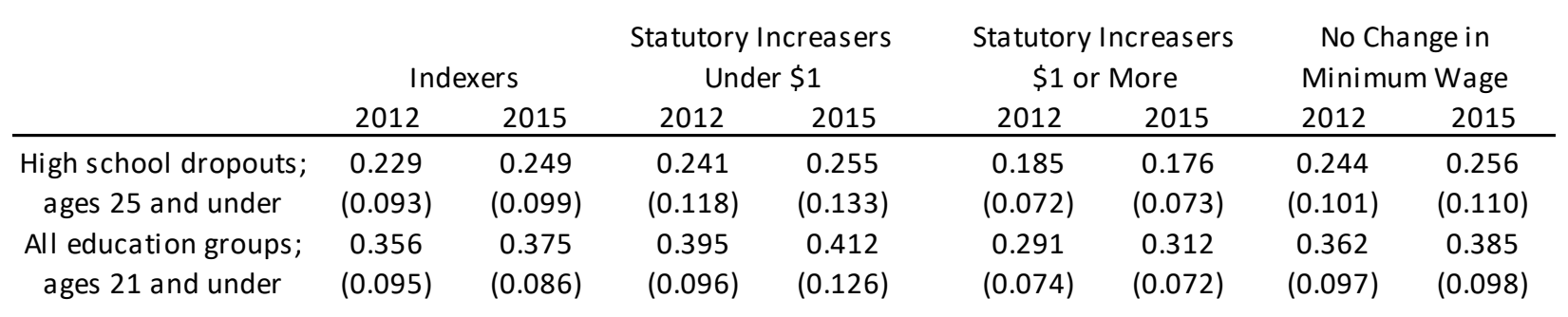

Panel B: Change between 2012 and 2015 for included controls

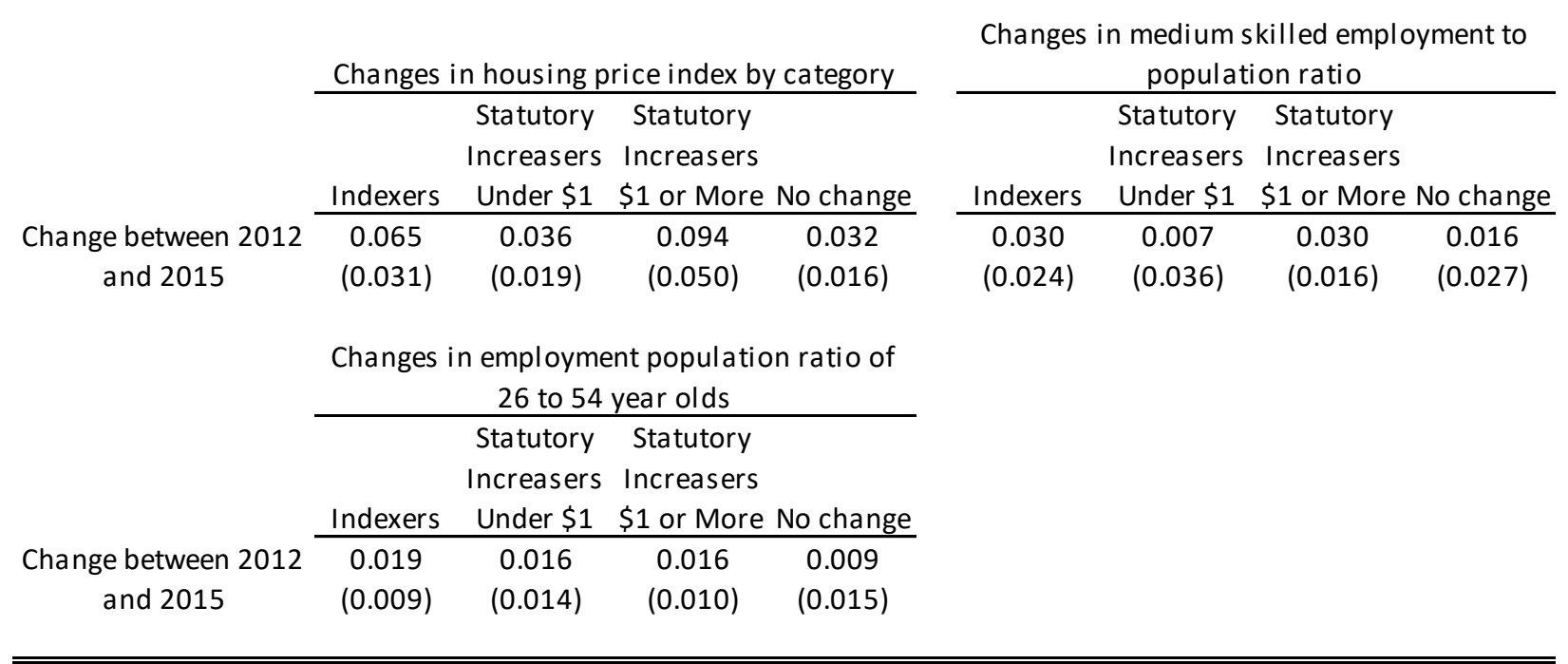

Panel A of this table reports summary statistics on the employment to population ratio for each of the four state treatment classifications and for each of the two subgroups we study. The employment to population ratio is calculated using the CPS MORG. Panel B reports changes between 2012 and 2015 by state classification of our control variables. These include the all transactions FHFA median house price index and the employment-topopulation ratio for medium skilled individuals. Medium skilled individuals are defined as high school graduates under 30 and high school dropouts between 30 and 65. The table also reports changes in employment rates among 26 to 54 year olds, who are used as within-state controls in our triple-difference specifications. Changes are calculated as the average in 2015 minus the average in 2012. 
Table 2B: Summary Statistics basic CPS data

Panel A: Employment-to-population ratio by group and state category

\begin{tabular}{|c|c|c|c|c|c|c|c|c|}
\hline & \multicolumn{2}{|c|}{ Indexers } & \multicolumn{2}{|c|}{$\begin{array}{c}\text { Statutory Increasers } \\
\text { Under } \$ 1\end{array}$} & \multicolumn{2}{|c|}{$\begin{array}{l}\text { Statutory Increasers } \\
\quad \$ 1 \text { or More }\end{array}$} & \multicolumn{2}{|c|}{$\begin{array}{l}\text { No Change in } \\
\text { Minimum Wage }\end{array}$} \\
\hline & 2012 & 2015 & 2012 & 2015 & 2012 & 2015 & 2012 & 2015 \\
\hline $\begin{array}{l}\text { High school dropouts; } \\
\text { ages } 25 \text { and under }\end{array}$ & $\begin{array}{c}0.237 \\
(0.071)\end{array}$ & $\begin{array}{c}0.262 \\
(0.069)\end{array}$ & $\begin{array}{c}0.233 \\
(0.081)\end{array}$ & $\begin{array}{c}0.265 \\
(0.108)\end{array}$ & $\begin{array}{c}0.192 \\
(0.048)\end{array}$ & $\begin{array}{c}0.194 \\
(0.054)\end{array}$ & $\begin{array}{c}0.254 \\
(0.072)\end{array}$ & $\begin{array}{c}0.267 \\
(0.076)\end{array}$ \\
\hline $\begin{array}{l}\text { All education groups; } \\
\text { ages } 21 \text { and under }\end{array}$ & $\begin{array}{c}0.362 \\
(0.064)\end{array}$ & $\begin{array}{c}0.387 \\
(0.070)\end{array}$ & $\begin{array}{c}0.401 \\
(0.074)\end{array}$ & $\begin{array}{c}0.415 \\
(0.095)\end{array}$ & $\begin{array}{c}0.294 \\
(0.053)\end{array}$ & $\begin{array}{c}0.320 \\
(0.059)\end{array}$ & $\begin{array}{c}0.373 \\
(0.073)\end{array}$ & $\begin{array}{c}0.393 \\
(0.075)\end{array}$ \\
\hline & Pan & Change & tween 20 & and 2015 & ncluded & trols & & \\
\hline
\end{tabular}

\begin{tabular}{|c|c|c|c|c|c|c|c|c|}
\hline & \multicolumn{4}{|c|}{ Changes in housing price index by category } & \multicolumn{4}{|c|}{$\begin{array}{c}\text { Changes in medium skilled employment to } \\
\text { population ratio }\end{array}$} \\
\hline & & Statutory & Statutory & & & Statutory & Statutory & \\
\hline & & Increasers & Increasers & & & Increasers & Increasers & \\
\hline & Indexers & Under \$1 & $\$ 1$ or & No change & Indexers & Under \$1 & $\$ 1$ or & No change \\
\hline Change between 2012 & 0.065 & 0.036 & 0.094 & 0.032 & 0.034 & 0.013 & 0.039 & 0.016 \\
\hline and 2015 & $(0.031)$ & $(0.019)$ & $(0.050)$ & $(0.016)$ & $(0.019)$ & $(0.028)$ & $(0.015)$ & $(0.024)$ \\
\hline
\end{tabular}

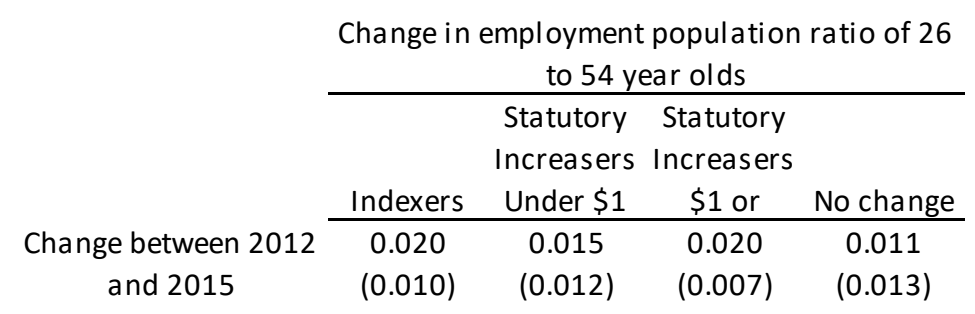

Panel A of this table reports summary statistics on the employment to population ratio for each of the four state treatment classifications and for each of the two subgroups we study. The employment to population ratio is calculated using the basic CPS. Panel B reports changes between 2012 and 2015 by state classification of our control variables. These include the all transactions FHFA median house price index and the employment-to-population ratio for medium skilled individuals. Medium skilled individuals are defined as high school graduates under 30 and high school dropouts between 30 and 65. The table also reports changes in employment rates among 26 to 54 year olds, who are used as within-state controls in our triple-difference specifications. Changes are calculated as the average in 2015 minus the average in 2012. 
Table 3A: Recent minimum wage increases and employment of high school dropouts under 25 using CPS-MORG data.

\begin{tabular}{|c|c|c|c|c|}
\hline & $(1)$ & $(2)$ & (3) & (4) \\
\hline \multirow[t]{2}{*}{ Indexer x Post } & 0.0054 & 0.0082 & 0.0077 & 0.0042 \\
\hline & $(0.011)$ & $(0.011)$ & $(0.011)$ & $(0.009)$ \\
\hline \multirow[t]{2}{*}{ Statutory Increaser x Post } & $-0.0206 * *$ & $-0.0169 *$ & $-0.0166^{*}$ & $-0.0182 * *$ \\
\hline & $(0.009)$ & $(0.010)$ & $(0.009)$ & $(0.008)$ \\
\hline \multirow[t]{2}{*}{ Housing Price Index Divided by 1000} & & -0.0968 & -0.1061 & -0.0516 \\
\hline & & $(0.102)$ & $(0.102)$ & $(0.087)$ \\
\hline \multirow[t]{2}{*}{ State mid-skill employment-to-population ratio } & & & $0.0638 * *$ & $0.0713^{* * *}$ \\
\hline & & & $(0.029)$ & $(0.026)$ \\
\hline Age and education controls & No & No & No & Yes \\
\hline Observations & 65,868 & 65,868 & 65,868 & 65,868 \\
\hline R-squared & 0.021 & 0.021 & 0.021 & 0.117 \\
\hline \multicolumn{5}{|c|}{$\begin{array}{l}\text { This table reports difference-in-differences estimates using the CPS MORG. The sample includes } \\
\text { teenagers and high school dropouts ages } 25 \text { and under. Mid-skill individuals are defined as those } 30 \\
\text { years old or younger with a high school degree, or as high school dropouts between the ages of } 30 \text { and } \\
65 \text {. All specifications include month and state fixed effects. Age and education controls consist of a } \\
\text { dummy variable for each education group and age. Standard errors are clustered at the state level. *** } \\
p<0.01, * * p<0.05, * p<0.1\end{array}$} \\
\hline
\end{tabular}


Table 3B: Recent minimum wage increases and employment of high school dropouts under 25 using basic CPS data.

\begin{tabular}{|c|c|c|c|c|}
\hline & (1) & (2) & (3) & (4) \\
\hline Indexer x Post & $\begin{array}{l}0.0064 \\
(0.010)\end{array}$ & $\begin{array}{l}0.0109 \\
(0.012)\end{array}$ & $\begin{array}{l}0.0095 \\
(0.012)\end{array}$ & $\begin{array}{l}0.0072 \\
(0.010)\end{array}$ \\
\hline Statutory Increaser x Post & $\begin{array}{l}-0.0135 \\
(0.010)\end{array}$ & $\begin{array}{l}-0.0075 \\
(0.008)\end{array}$ & $\begin{array}{l}-0.0081 \\
(0.008)\end{array}$ & $\begin{array}{l}-0.0080 \\
(0.007)\end{array}$ \\
\hline Housing Price Index Divided by 1000 & & $\begin{array}{l}-0.1550 \\
(0.106)\end{array}$ & $\begin{array}{r}-0.1657 \\
(0.107)\end{array}$ & $\begin{array}{r}-0.1152 \\
(0.088)\end{array}$ \\
\hline State mid-skill employment-to-population ratio & & & $\begin{array}{c}0.0981 * * * \\
(0.037)\end{array}$ & $\begin{array}{c}0.1233 * * * \\
(0.035)\end{array}$ \\
\hline Age and education controls & No & No & No & Yes \\
\hline Observations & 258,780 & 258,780 & 258,780 & 258,780 \\
\hline R-squared & 0.019 & 0.019 & 0.019 & 0.113 \\
\hline \multicolumn{5}{|c|}{$\begin{array}{l}\text { This table reports difference-in-differences estimates using the basic CPS. The sample includes } \\
\text { teenagers and high school dropouts ages } 25 \text { and under. Mid-skill individuals are defined as those } 30 \\
\text { years old or younger with a high school degree, or as high school dropouts between the ages of } 30 \text { and } \\
65 \text {. All specifications include month and state fixed effects. Age and education controls consist of a } \\
\text { dummy variable for each education group and age. Standard errors clustered at the state level. }{ }^{* * *} \\
p<0.01,{ }^{* *} p<0.05, * p<0.1\end{array}$} \\
\hline
\end{tabular}


Table 4A: Recent minimum wage increases and employment of individuals 21 and under using CPS-MORG data. Includes individuals of all education groups.

$$
\text { (1) }
$$

(3)

-0.0116
$(0.009)$
-0.0047
$(0.011)$

Housing Price Index Divided by 1000

State mid-skill employment-to-population ratio

$$
\begin{array}{ccc}
-0.0220^{* *} & -0.0235^{* * *} & -0.0057 \\
(0.009) & (0.008) & (0.009) \\
-0.0184^{*} & -0.0173^{*} & -0.0141 \\
(0.010) & (0.010) & (0.009) \\
0.3498^{* * *} & 0.3134^{* * *} & 0.1862^{*} \\
(0.093) & (0.096) & (0.098) \\
& 0.2410^{* * *} & 0.2500^{* * *} \\
& (0.021) & (0.022)
\end{array}
$$

Age and education controls

No

No

No $\quad$ Yes

Observations

120,748

120,748

0.021

$\begin{array}{cc}120,748 & 120,748 \\ 0.022 & 0.157\end{array}$

This table reports difference-in-differences estimates on a sample including all individuals ages 16 to 21 in the CPS MORG. Mid-skill individuals are defined as those 30 years old or younger with a high school degree, or high school dropouts between the ages of 30 and 65 . All specifications include month and state fixed effects. Age and education controls consist of a dummy variable for each education group and age. Standard errors are clustered at the state level. ${ }^{* * *} p<0.01,{ }^{* *} p<0.05$, $* p<0.1$ 
Table 4B: Recent minimum wage increases and employment of individuals 21 and under using basic CPS data. Includes individuals of all education groups.

(2)

(3)

(4)

\begin{tabular}{lcccc} 
Indexer x Post & -0.0037 & -0.0103 & -0.0158 & 0.0005 \\
& $(0.010)$ & $(0.010)$ & $(0.010)$ & $(0.010)$ \\
Statutory Increaser x Post & -0.0039 & $-0.0129^{*}$ & $-0.0148^{*}$ & -0.0106 \\
& $(0.009)$ & $(0.008)$ & $(0.008)$ & $(0.007)$ \\
Housing Price Index Divided by 1000 & & $0.2274^{* * *}$ & $0.1839^{* *}$ & 0.0801 \\
& & $(0.080)$ & $(0.083)$ & $(0.085)$ \\
State mid-skill employment-to-population ratio & & & $0.3791^{* * *}$ & $0.3821^{* * *}$ \\
& & & $(0.030)$ & $(0.030)$ \\
Age and education controls & No & No & No & Yes \\
Observations & & & & \\
R-squared & 480,583 & 480,583 & 480,583 & 480,583 \\
\hline \hline
\end{tabular}

This table reports difference-in-differences estimates run on a sample that includes all individuals ages 16 to 21 in the basic CPS. Mid-skill individuals are defined as those thirty years old or younger with a high school degree, or high school dropouts between the ages of 30 and 65 . All specifications include month and state fixed effects. Age and education controls consist of a dummy variable for each education group and age. Standard errors are clustered the state level. *** $p<0.01,{ }^{* *} p<0.05,{ }^{*} p<0.1$ 


\section{Table 5A: Recent minimum wage increases above and below $\$ 1$ and employment of high school dropouts under 25 using CPS-MORG data.}

(1)

Indexer x Post
Large Statutory Increaser x Post
Small Statutory Increaser x Post
Housing Price Index Divided by 1000
State mid-skill employment-to-population ratio

0.0054

(0.011)

$-0.0269 * * *$

(0.008)

$-0.0060$

(0.014)

(2)

(3)

(4)

Age and education controls

Observations

R-squared

This table rep that increased their minimum wage by a dollar or more. The sample is taken from the CPS MORG, and includes teenagers and high school dropouts ages 25 and under. Mid-skill individuals are defined as those thirty years old or younger with a high school degree, or high school dropouts between the ages of 30 and 65. All specifications include month and state fixed effects. Age and education controls consist of a dummy variable for each education group and age. Standard errors are clustered at the state level. $* * * p<0.01, * * p<0.05, * p<0.1$ 
Table 5B: Recent minimum wage increases above and below $\$ 1$ and employment of high school dropouts under 25 using basic CPS data.

\begin{tabular}{|c|c|c|c|c|}
\hline & (1) & $(2)$ & (3) & (4) \\
\hline Indexer x Post & $\begin{array}{l}0.0064 \\
(0.010)\end{array}$ & $\begin{array}{l}0.0095 \\
(0.012)\end{array}$ & $\begin{array}{l}0.0078 \\
(0.012)\end{array}$ & $\begin{array}{l}0.0066 \\
(0.010)\end{array}$ \\
\hline Large Statutory Increaser x Post & $\begin{array}{c}-0.0204^{* *} \\
(0.009)\end{array}$ & $\begin{array}{c}-0.0147^{*} \\
(0.008)\end{array}$ & $\begin{array}{c}-0.0160 * * \\
(0.007)\end{array}$ & $\begin{array}{r}-0.0111 \\
(0.007)\end{array}$ \\
\hline Small Statutory Increaser x Post & $\begin{array}{l}0.0025 \\
(0.014)\end{array}$ & $\begin{array}{l}0.0027 \\
(0.014)\end{array}$ & $\begin{array}{l}0.0033 \\
(0.014)\end{array}$ & $\begin{array}{r}-0.0034 \\
(0.010)\end{array}$ \\
\hline Housing Price Index Divided by 1000 & & $\begin{array}{l}-0.1055 \\
(0.109)\end{array}$ & $\begin{array}{r}-0.1114 \\
(0.109)\end{array}$ & $\begin{array}{r}-0.0934 \\
(0.094)\end{array}$ \\
\hline State mid-skill employment-to-population ratio & & & $\begin{array}{c}0.1021^{* * *} \\
(0.036)\end{array}$ & $\begin{array}{c}0.1249 * * * \\
(0.034)\end{array}$ \\
\hline Age and education controls & No & No & No & Yes \\
\hline Observations & 258,780 & 258,780 & 258,780 & 258,780 \\
\hline R-squared & 0.019 & 0.019 & 0.019 & 0.113 \\
\hline \multicolumn{5}{|c|}{$\begin{array}{l}\text { This table reports difference-in-differences estimates for which the policy indicator variables } \\
\text { distinguish between states in which the minimum wage was increased by less than a dollar and states } \\
\text { that increased their minimum wage by a dollar or more. The sample is taken from the basic CPS, and } \\
\text { includes teenagers and high school dropouts ages } 25 \text { and under. Mid-skill individuals are defined as } \\
\text { those thirty years old or younger with a high school degree, or high school dropouts between the ages } \\
\text { of } 30 \text { and } 65 \text {. All specifications include month and state fixed effects. Age and education controls } \\
\text { consist of a dummy variable for each education group and age. Standard errors are clustered at the } \\
\text { state level. }{ }^{* * *} p<0.01,{ }^{* *} p<0.05,{ }^{*} p<0.1\end{array}$} \\
\hline
\end{tabular}




\section{Table 6A: Recent minimum wage increases above and below $\$ 1$ and employment of individuals 21 and under using CPS MORG data. Includes individuals of all education groups.}

\begin{tabular}{|c|c|c|c|c|}
\hline & (1) & $(2)$ & (3) & (4) \\
\hline \multirow[t]{2}{*}{ Indexer x Post } & -0.0116 & $-0.0236 * *$ & $-0.0254 * * *$ & -0.0076 \\
\hline & $(0.009)$ & $(0.009)$ & $(0.008)$ & $(0.009)$ \\
\hline \multirow[t]{2}{*}{ Statutory Increaser Large x Post } & -0.0042 & $-0.0263 * *$ & $-0.0262 * *$ & $-0.0230 * *$ \\
\hline & $(0.015)$ & $(0.011)$ & $(0.011)$ & $(0.010)$ \\
\hline \multirow[t]{2}{*}{ Statutory Increaser Small x Post } & -0.0059 & -0.0071 & -0.0043 & -0.0011 \\
\hline & $(0.012)$ & $(0.011)$ & $(0.010)$ & $(0.008)$ \\
\hline \multirow[t]{2}{*}{ Housing Price Index Divided by 1000} & & $0.4054^{* * *}$ & $0.3767^{* * *}$ & $0.2495 * *$ \\
\hline & & $(0.102)$ & $(0.102)$ & $(0.104)$ \\
\hline \multirow[t]{2}{*}{ State mid-skill employment-to-population ratio } & & & $0.2417 * * *$ & $0.2507^{* * *}$ \\
\hline & & & $(0.021)$ & $(0.022)$ \\
\hline Age and education controls & No & No & No & Yes \\
\hline Observations & 120,748 & 120,748 & 120,748 & 120,748 \\
\hline R-squared & 0.021 & 0.021 & 0.022 & 0.157 \\
\hline
\end{tabular}

This table reports difference-in-differences estimates for which the policy indicator variables distinguish between states in which the minimum wage was increased by less than a dollar and states that increased their minimum wage by a dollar or more. The sample consists of all individuals ages 16 to 21 in the CPS MORG. Mid-skill individuals are defined as those thirty years old or younger with a high school degree, or high school dropouts between the ages of 30 and 65 . All specifications include month and state fixed effects. Age and education controls consist of a dummy variable for each education group and age. Standard errors clustered at the state level. ${ }^{* * *} p<0.01,{ }^{* *} p<0.05,{ }^{*}$ $\mathrm{p}<0.1$ 


\section{Table 6B: Recent minimum wage increases above and below $\$ 1$ and employment of individuals 21 and under using basic CPS data. Includes individuals of all education groups.}

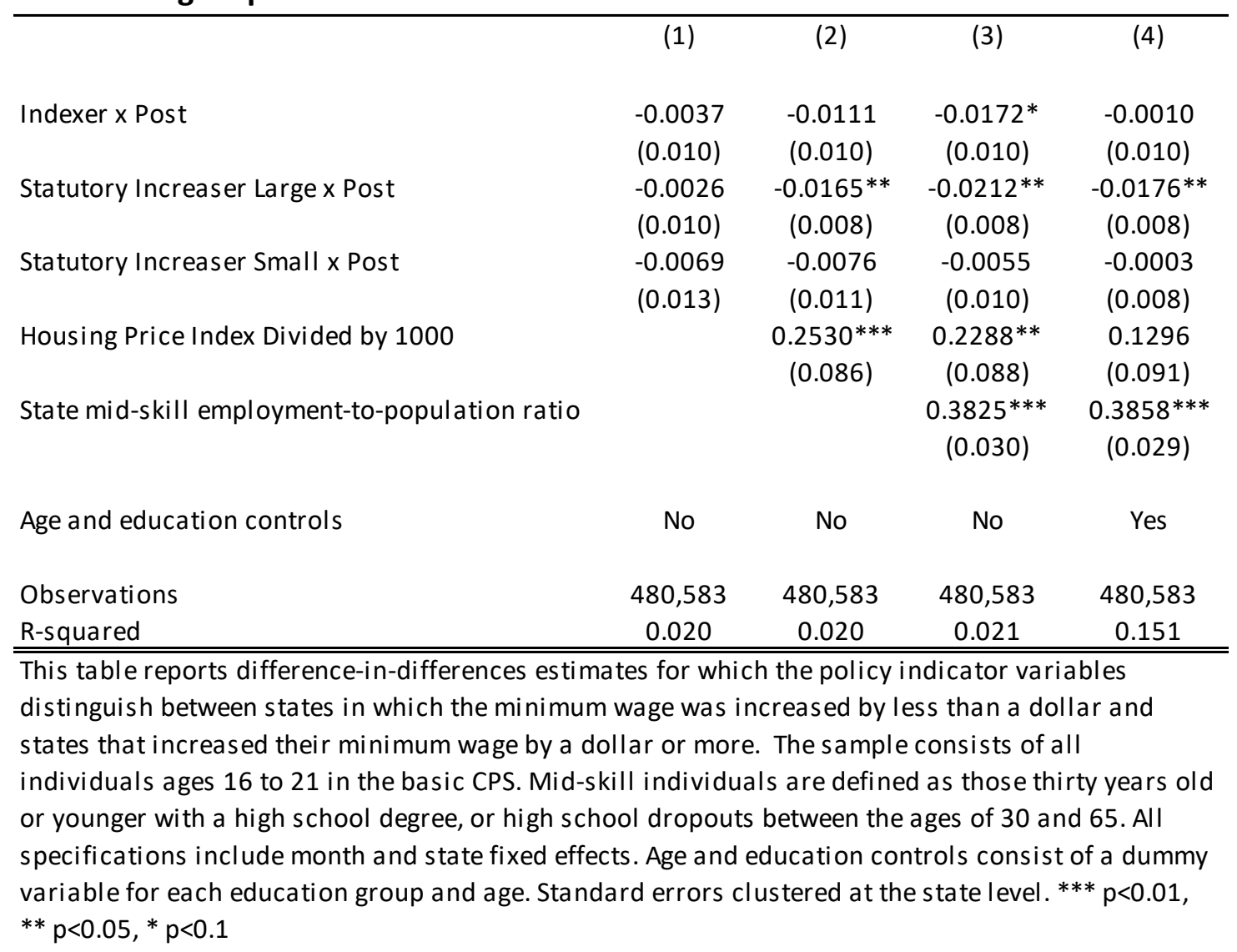




\section{Table 7A: Triple differences results for dropouts $\mathbf{2 5}$ and under with individuals ages}

26 to 54 within-state control group using CPS MORG data.

\begin{tabular}{|c|c|c|c|c|}
\hline & \multicolumn{2}{|c|}{$\begin{array}{c}\text { Panel A: Large and small } \\
\text { statutory increasers } \\
\text { separated into two } \\
\text { treatment variables }\end{array}$} & \multicolumn{2}{|c|}{$\begin{array}{l}\text { Panel B: All statutory } \\
\text { increasers included } \\
\text { together in one } \\
\text { treatment variable }\end{array}$} \\
\hline & (1) & (2) & (3) & (4) \\
\hline Treated $\mathrm{x}$ Indexer $\mathrm{x}$ Post & $\begin{array}{r}-0.0009 \\
(0.013)\end{array}$ & $\begin{array}{r}-0.0038 \\
(0.010)\end{array}$ & $\begin{array}{r}-0.0009 \\
(0.013)\end{array}$ & $\begin{array}{l}-0.0038 \\
(0.010)\end{array}$ \\
\hline Treated $\mathrm{x}$ Large Statutory Increaser $\mathrm{x}$ Post & $\begin{array}{c}-0.0309 * * * \\
(0.007)\end{array}$ & $\begin{array}{c}-0.0272^{* * *} \\
(0.006)\end{array}$ & & \\
\hline Treated $\times$ Small Statutory Increaser x Post & $\begin{array}{r}-0.0101 \\
(0.014)\end{array}$ & $\begin{array}{r}-0.0166 \\
(0.011)\end{array}$ & & \\
\hline Treated $\mathrm{x}$ Statutory Increaser $\mathrm{x}$ Post & & & $\begin{array}{c}-0.0246^{* * *} \\
(0.009)\end{array}$ & $\begin{array}{c}-0.0240 * * * \\
(0.007)\end{array}$ \\
\hline Age and education controls & No & Yes & No & Yes \\
\hline Observations & 678,286 & 678,286 & 678,286 & 678,286 \\
\hline R-squared & 0.134 & 0.172 & 0.134 & 0.172 \\
\hline \multicolumn{5}{|c|}{$\begin{array}{l}\text { This table reports triple-difference estimates in which the treatment group consists of teenagers and } \\
\text { high-school dropouts ages } 25 \text { and under. The within-state control group consists of individuals ages } \\
26 \text { to } 54 \text {. Samples are taken from the CPS MORG. Mid-skill individuals are defined as those } 30 \text { years } \\
\text { old or younger with a high school degree, or high school dropouts between the ages of } 30 \text { and } 65 \text {. All } \\
\text { specifications include month and state fixed effects. Age and education controls consist of a dummy } \\
\text { variable for each education group and age. Standard errors are clustered at the state level. }{ }^{* * *} \text { p }<0.01 \text {, } \\
* * \text { p }<0.05, * p<0.1\end{array}$} \\
\hline
\end{tabular}


Table 7B: Triple differences results for dropouts under 25 with individuals ages 26 to 54 within-state control group using basic CPS data.

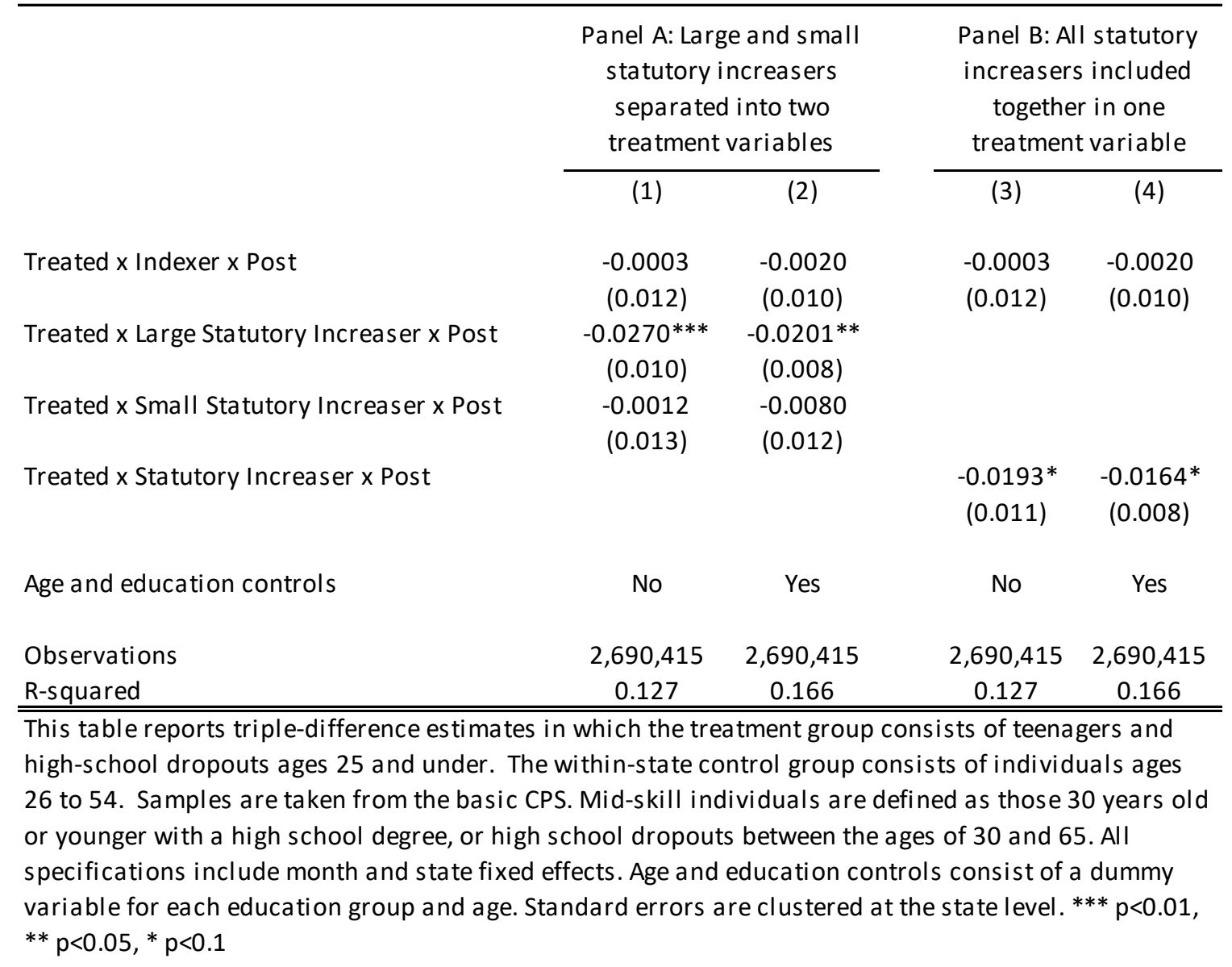




\section{Table 8A: Triple differences results for individuals 21 and under with individuals}

age 26 to 54 within-state control group using CPS MORG data.

\begin{tabular}{|c|c|c|c|c|}
\hline & \multicolumn{2}{|c|}{$\begin{array}{c}\text { Panel A: Large and small } \\
\text { statutory increasers } \\
\text { separated into two } \\
\text { treatment variables }\end{array}$} & \multicolumn{2}{|c|}{$\begin{array}{l}\text { Panel B: All statutory } \\
\text { increasers included } \\
\text { together in one } \\
\text { treatment variable }\end{array}$} \\
\hline & $(1)$ & $(2)$ & (3) & (4) \\
\hline \multirow[t]{2}{*}{ Treated $\mathrm{x}$ Indexer $\mathrm{x}$ Post } & -0.0178 & -0.0040 & -0.0178 & -0.0040 \\
\hline & $(0.011)$ & $(0.010)$ & $(0.011)$ & $(0.010)$ \\
\hline \multirow[t]{2}{*}{ Treated x Large Statutory Increaser x Post } & -0.0070 & -0.0106 & & \\
\hline & $(0.016)$ & $(0.011)$ & & \\
\hline \multirow[t]{2}{*}{ Treated $x$ Small Statutory Increaser $x$ Post } & -0.0110 & -0.0092 & & \\
\hline & $(0.011)$ & $(0.009)$ & & \\
\hline \multirow[t]{2}{*}{ Treated $\mathrm{x}$ Statutory Increaser $\mathrm{x}$ Post } & & & -0.0082 & -0.0102 \\
\hline & & & $(0.012)$ & $(0.009)$ \\
\hline Age and education controls & No & Yes & No & Yes \\
\hline Observations & 733,166 & 733,166 & 733,166 & 733,166 \\
\hline R-squared & 0.121 & 0.173 & 0.121 & 0.173 \\
\hline \multicolumn{5}{|c|}{$\begin{array}{l}\text { This table reports triple-difference estimates in which the treatment group consists of all individuals } \\
\text { ages } 16 \text { to } 21 \text {. The within-state control group consists of individuals ages } 26 \text { to } 54 \text {. Samples are } \\
\text { taken from the CPS MORG. Mid-skill individuals are defined as those } 30 \text { years old or younger with a } \\
\text { high school degree, or high school dropouts between the ages of } 30 \text { and } 65 \text {. All specifications include } \\
\text { month and state fixed effects. Age and education controls consist of a dummy variable for each } \\
\text { education group and age. Standard errors are clustered at the state level. }{ }^{* * *} p<0.01, * * p<0.05, * \\
p<0.1\end{array}$} \\
\hline
\end{tabular}


Table 8B: Triple differences results for individuals 21 and under with individuals age 26 to 54 within-state control group using basic CPS data.

\begin{tabular}{|c|c|c|c|c|}
\hline & \multicolumn{2}{|c|}{$\begin{array}{c}\text { Panel A: Large and small } \\
\text { statutory increasers } \\
\text { separated into two } \\
\text { treatment variables }\end{array}$} & \multicolumn{2}{|c|}{$\begin{array}{c}\text { Panel B: All statutory } \\
\text { increasers included } \\
\text { together in one treatment } \\
\text { variable }\end{array}$} \\
\hline & (1) & $(2)$ & (3) & (4) \\
\hline \multirow[t]{2}{*}{ Treated $\mathrm{x}$ Indexer $\mathrm{x}$ Post } & -0.0106 & 0.0022 & -0.0106 & 0.0022 \\
\hline & $(0.012)$ & $(0.011)$ & $(0.012)$ & $(0.011)$ \\
\hline \multirow[t]{2}{*}{ Treated x Large Statutory Increaser x Post } & -0.0088 & -0.0100 & & \\
\hline & $(0.010)$ & $(0.007)$ & & \\
\hline \multirow[t]{2}{*}{ Treated x Small Statutory Increaser x Post } & -0.0110 & -0.0063 & & \\
\hline & $(0.011)$ & $(0.009)$ & & \\
\hline \multirow[t]{2}{*}{ Treated x Statutory Increaser x Post } & & & -0.0094 & -0.0089 \\
\hline & & & $(0.008)$ & $(0.006)$ \\
\hline Age and education controls & No & Yes & No & Yes \\
\hline Observations & $2,912,218$ & $2,912,218$ & $2,912,218$ & $2,912,218$ \\
\hline R-squared & 0.114 & 0.166 & 0.114 & 0.166 \\
\hline
\end{tabular}

This table reports triple-difference estimates in which the treatment group consists of all individuals ages 16 to 21 . The within-state control group consists of individuals ages 26 to 54 . Samples are taken from the basic CPS. Mid-skill individuals are defined as those 30 years old or younger with a high school degree, or high school dropouts between the ages of 30 and 65. All specifications include month and state fixed effects. Age and education controls consist of a dummy variable for each education group and age. Standard errors are clustered at the state level. ${ }^{* * *} p<0.01, * * p<0.05, * p<0.1$ 


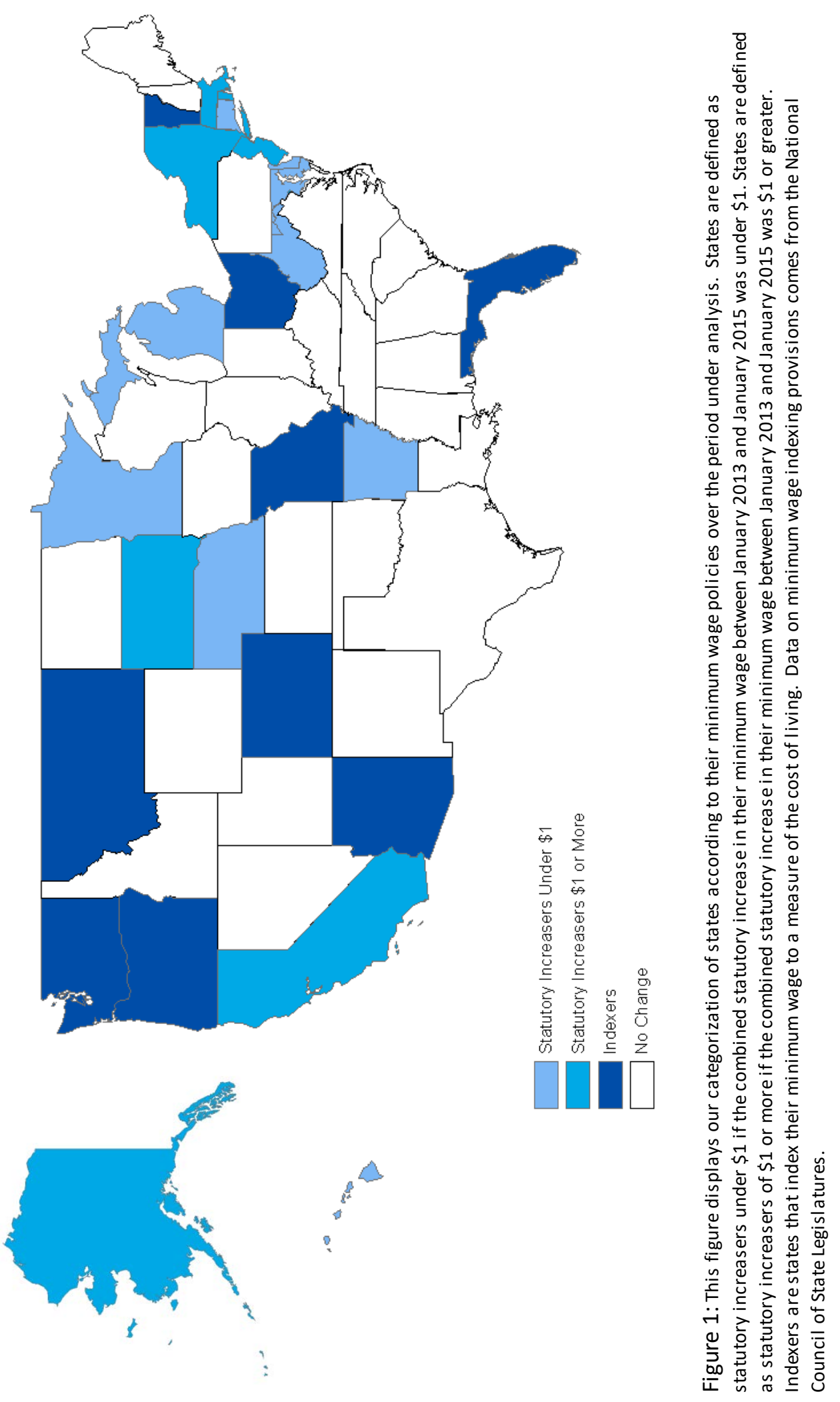




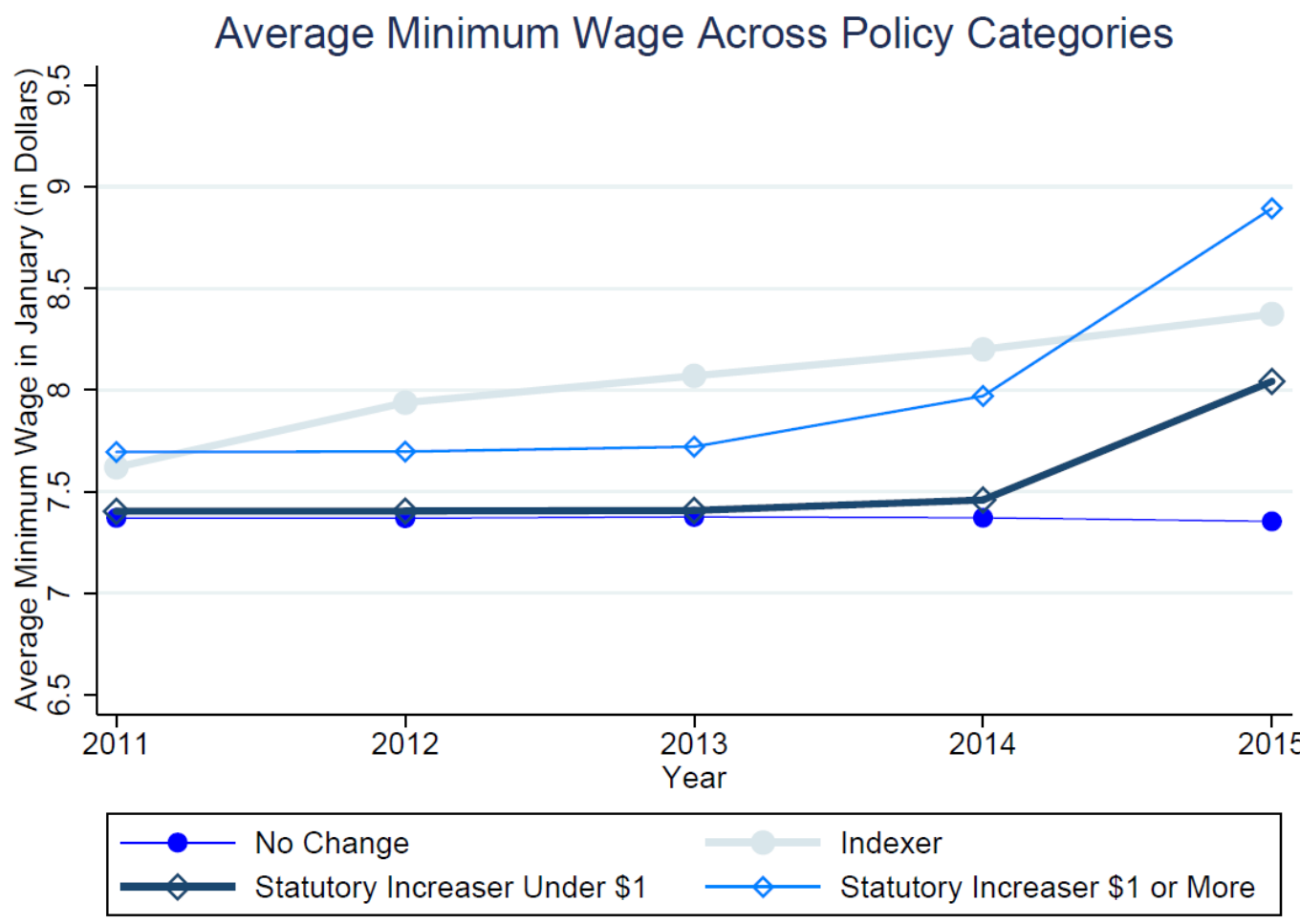

Figure 2: This figure plots the average annual effective minimum wage for states in each of the four state minimum wage policy categories from January 2011 to January 2015. States are defined as statutory increasers under $\$ 1$ if the combined statutory increase in their minimum wage between January 2013 and January 2015 was under $\$ 1$. States are defined as statutory increasers of $\$ 1$ or more if the combined statutory increase in their minimum wage was $\$ 1$ or greater. Indexers are states that index their minimum wage to inflation. The effective minimum wage is defined as the maximum of the state and federal minimum wage. Data on minimum wage rates comes from the US Department of Labor. Data on minimum wage policies comes from the National Conference of State Legislatures. 


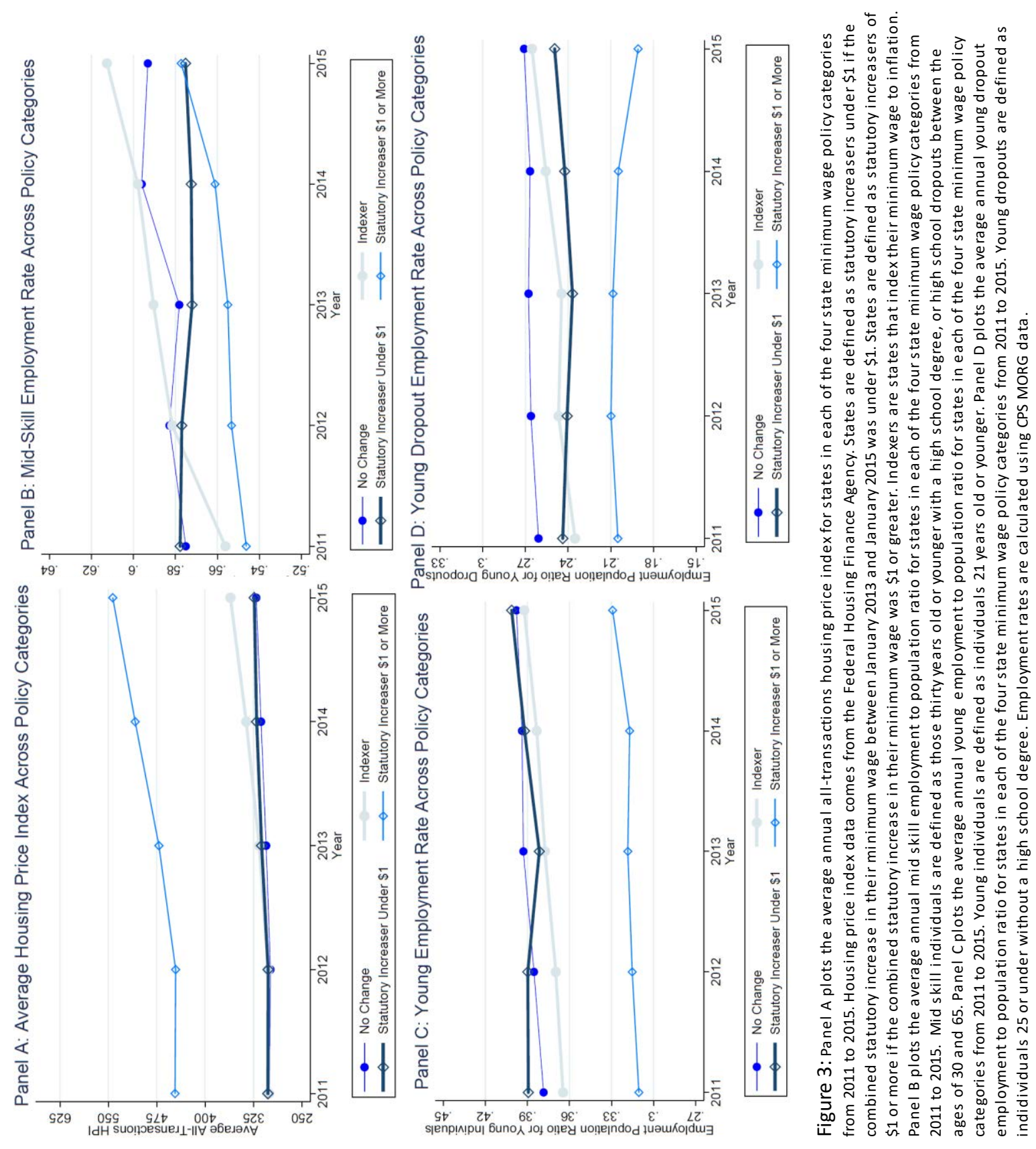



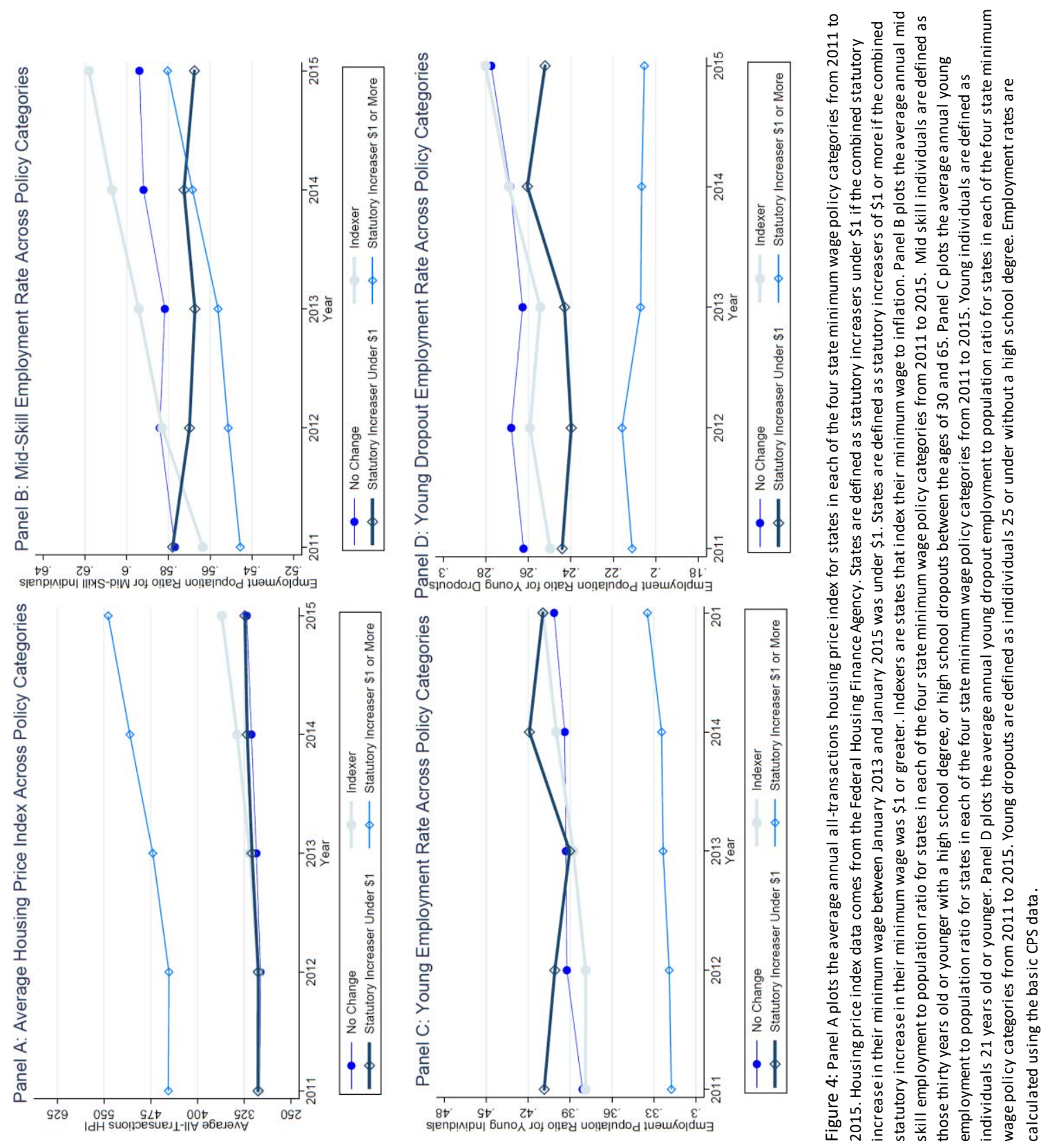